NBSIR 79-1771

An Investigation of Preferences
for Various Types of Energy
Cost Feedback

Ann Ramey-Smith

Jennifer L. Gagnon

Consumer Sciences Division

Center for Consumer Product Technology

National Bureau of Standards

Washington, D.C. 20234

February 1979

Final Report

Issued August 1979

Prepared for

100

U.S. Department of Energy

.456

$7 y-1771$

C. 2 



\section{AN INVESTIGATION OF PREFERENCES FOR VARIOUS TYPES OF ENERGY COST FEEDBACK}

Ann Ramey-Smith Jennifer L. Gagnon

Consumer Sciences Division

Center for Consumer Product Technology

National Bureau of Standards

Washington, D.C. 20234

February 1979

Final Report

Issued August 1979

Prepared for

U.S. Department of Energy

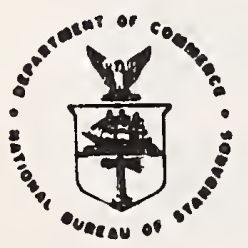

U.S. DEPARTMENT OF COMMERCE, Juanita M. Kreps, Secretary Luther H. Hodges, Jr., Under Secretary

Jordan J. Baruch, Assistant Secretary for Science and Technology

NATIONAL BUREAU OF STANDARDS. Ernest Ambler, Director 
Page

List of Tables

List of figures . . . . . . . . . . . . . . iii

Acknowledgments . . . . . . . . . . . . . v

Abstract . . . . . . . . . . . . . . v vii

Introduction . . . . . . . . . . . . . . 1

Background ................... 1

Present Study ................... 2

Feedback Displays . . . . . . . . . . . . 3

Procedure .. . . . . . . . . . . . . . 4

Participants . . . . . . . . . . . . . . 4

Apparatus . . . . . . . . . . . . . . 4

Experimental Tasks . . . . . . . . . . . 7

Participant Response Categories . . . . . . . 10

Results . . . . . . . . . . . . . . . 12

Awareness-Attitudes Toward Energy Conservation . . 12

Response Categories . . . . . . . . . . 12

Cumulative Feedback Summary and Conclusions . . . 24

Instantaneous Feedback Sumnary and Conclusions . . 25

Projected Feedback Summary and Conclusions . . . 26

DOE Prototype Meter Summary and Conclusions . . . 27

Participants' Own Designs ............ 28

Discussion . . . . . . . . . . . . . . 29

Related Research and Recommendations . . . . 29

Future Research Areas . . . . . . . . . 32

References . . . . . . . . . . . 34

Appendices . . . . . . . . . . . . . 35

Appendix A, Table 1--Appliance Energy Cost Values

Displayed for Cumulative Feedback . . . . . 35

Appendix A, Table 2--Appliance Energy Cost Values

Displayed for Instantaneous Feedback . . . . . 36

Appendix A, Table 3--Appliance Energy Cost Values Displayed for Projected Feedback . . . . . . 
Appendix A, Table 4--Iiterature Sources for Energy Cost Estimates

Appendix B--Energy Usage Questionnaire . . . . .

Appendix C--Feedback Explanation . . . . . . . . 43

Appendix D--Equipment Explanation . . . . . . . . 47

Appendix E--Cumulative Feedback Interview Guide . . 49

Appendix F--Instantaneous Feedback Interview Guide. $\quad 51$

Appendix G--Projected Feedback Interview Guide • • 53

Appendix H--Meter Design Interview Guide . • • . 55

Appendix I--DOE Prototype Meter Interview Guide • • 57

Appendix J--Final Interview . . . . . . . . . . 59

Appendix K--Human Factors Considerations for Energy Feedback Meters . . . . . . . . . . . . . .

Appendix L--A Proposal for Field Testing Energy

Cost Feedback Meters . . . . . . . . . . 


\section{List of Tables}

Table

$\underline{\text { Page }}$

1 Participant Demographics . . . . . . 5

2 Feedback Conditions . . . . . . . . 9

3 Understandability of the Purpose . . . . 13

4 Understandability of the Derivation . . . 15

5 Usability for Budgeting . . . . . . 17

6 Usability for Monitoring Individual Appliance Use.......... . . 19

7 Usability for Comparing Patterns of Energy Use . . . . . . . . . . . . 21

8 Meaningfulness ........... 23

List of Figures

Figure

$\underline{\text { Page }}$

1 Interactive Terminal and Feedback Display

Panel . . . . . . . . . . 6 



\section{Acknowledgments}

The authors of this report wish to acknowledge the assistance of J.J. Persensky and John V. Fechter, Jr. in the preliminary stages of the study's design, Robert Kershner and George Lapinsky for their aid in data collection and reduction, the staff of the Advanced Measurement Technology Group at NBS for equipment design and construction, and Michael Vogt of the center for Building Technology at iNBS for the development of the required computer programs. Thanks are also due Bonnie Matteson, Carol Mullinix, and Kim Leaman for secretarial support. 

The present study addressed the issue of consumer preferences for various types of energy cost feedback for individual consumers. Its purpose was to provide human factors recommendations to DOE related to the performance characteristics of energy cost feedback devices for use by DOE in testing energy cost feedback meters. Simulation and interview techniques were used to provide consumer reaction to cumulative, instantaneous, and projected feedback presented as dollar and cent values. A majority of participants indicated a preference for cumulative feedback types. All types of cumulative feedback are easily understood, accurate in reflecting actual energy consumption and suitable to several uses. Hourly instantaneous feedback was considered useful for monitoring energy use of individual appliances. All participants having two energy sources in their home expressed a preference for having feedback presented as separate cost figures rather than as a total cost. Recommendations for feedback types as well as some performance characteristics of energy cost feedback meters for further testing by DOE are discussed.
\end{abstract}



Background

Within the Department of Energy (DOE), the Division of Buildings and Community systems, Office of the Assistant Secretary for Conservation and Solar Applications, has responsibility for encouraging more efficient use of energy in the building sector. It is becoming more evident that motivating the consuming public, as well as developing new technologies, is a crucial dimension to the conservation effort. One strategy currently being developed involves the concept of feedback. In this context feedback means providing homeowners with immediate and understandable information on their energy costs will allow them to better control their energy using activities.

In research funded by DOE's Consumer Motivation Branch and conducted by Princeton University, a series of experiments tested this concept. Seligman, Darley, and Becker (1976) performed four feedback experiments designed to: (1) modify the rate of summer electricity usage by providing homeowners daily feedback on electricity usage as compared to their previous month's consumption; (2) examine the effects of setting specific energy conservation goals on electricity consumption: and, (3) determine the extent of energy consumption when a homeowner's energy consumption feedback involved a comparison to other peoples energy consumption. Seligman et al. concluded that feedback facilitates a reduction of energy consumption but that the optimal nature of the feedback system had not been identified.

Since then, a number of other research projects have addressed the issue of feedback. For example, Winett, Kaiser, and Haberkorn (in press) investigated daily feedback and rebate systems on energy used by lighting, appliances, and air-conditioning. Their results indicate that daily feedback is effective in reducing electricity consumption when preceded by a rebate system for reductions in electricity use. However, the effects of feedback alone were inconclusive. Consequently, Winett, Neale, Williams, Yokley, and Kauder (1977) evaluated three kinds of daily written cumulative feedback systems; i.e., individual feedback, group feedback (based on energy used by similar types of residences), and the combination of individual and group feedback. The feedback presented was kWh use for the prior day and the percent increase or decrease from the baseline use and contained a projective feedback component. Winett et al. found that the combination of individual and group 
feedback was best in reducing electricity consumption, while group feedback alone was the most ineffective of the three types of feedback.

The Consumer Motivation Branch of the Department of Energy, in cooperation with Potomac Electric Power Company (PEPCO) and with research support from Princeton University, is currently testing the effectiveness of a simple feedback monitor which provides homeowners with a display that alternates, at four second intervals, time of day and centsper-hour of total household electricity use (i.e., "Your electricity cost for the next hour will be $\$ 0.742$ if you continue to use electricity at your present rate."). This field experiment involves 140 PEPCO customers (70 control and 70 experimental) and will run for one year. It is not designed to address the question of the most effective type of feedback, but rather as a preliminary study to advance knowledge in the area of feedback as it relates to customer acceptance, utility roles, and technical considerations.

Present Study

As an initial investigation of the issue of effective energy feedback, the present study provided consumer input to the human factors design of energy feedback meters. Toward this purpose, several assumptions are made. These are:

(a) Energy feedback meters are an effective means of reducing energy consumption;

(b) The meters in question will be consumer-oriented rather than for use by industry;

(c) The meters will provide energy-use information specific to the individual consumer as opposed to a group; and,

(d) The energy-use information will be presented as cost figures rather than as, for example, kWh.

The purpose of the present study is to provide human factors recommendations related to the performance characteristics of energy-cost feedback devices. Role-playing and interviewing techniques are used to provide consumer reaction to various types of energy cost feedback. The issues addressed include:

1. The meaningfulness/usability of the displayed energy feedback information: 
2. The design characteristics of the meter itself; and,

3. Educational or instructional materials which should accompany the feedback meters in field testing.

This report presents findings regarding the first issue above, with a brief discussion of human factors recommendations for design characteristics contained in Appendix $K$. The issue of educational and instructional materials will be addressed in a separate report.

\section{Feedback Displays}

The three types of energy-cost feedback to which participants were exposed include cumulative, instantaneous, and projected feedback presented as dollar and cent values. For all three types of feedback, energy cost was presented as a total energy cost or was broken down into gas and electric costs separately. These three feedback types are defined below as they were conceptualized for this study.

A cumulative feedback meter constantly monitors energy usage and displays a running accumulation of the cost of energy consumption for daily, weekly, or monthly time periods. At the end of the time period, the display resets and the accumulation begins again. Without any prior knowledge of how consumers would use cumulative feedback, it was hypothesized that this type of information would be most useful for budgeting energy expenditures and for making comparisons of energy use on a day-to-day basis.

An instantaneous energy-cost feedback meter monitors the rate of present energy usage and estimates what the cost would be if consumption continued at that rate for one hour, one day, or one month. The meter samples energy use and updates the display every 15 seconds. It was hypothesized that consumers could use instantaneous feedback as an indicator of the energy consumption of various individual appliances or behaviors.

The third type of energy cost feedback is projected feedback. Projected feedback is based on the previous day's energy cost which is used to estimate the energy cost for the following day, week, or month. The values displayed for each time period change each day based on the energy cost of the previous day. Project feedback, 
as used in the present study, was hypothesized to serve as an estimate for use in budgeting energy use and cost for up to one month.

\section{PROCEDURE}

\section{Participants}

Eighteen participants were tested during a five-week period. Participants were selected such that each of the following age groups contained six participants: 25-39 years, 40-54 years, and 55+ years. All participants were residents of the Washington, D.C. metropolitan area and are not intended to be statistically representative of energy consumers nationwide.

Except for the 55+ years group in which three participants had gas and electric homes and one had an oil and electric home, each group had two participants who lived in allelectric homes, two in oil and electric homes, and two in gas and electric homes. While it was not possible within each category to have a range among the participants of the percentage of take-home pay spent on utilities, a range of two percent to 20 percent did exist across age groups and home energy source categories. Table 1 presents a summary of the demographic characteristics of the study participants.

Each participant was tested for two hours per day for four consecutive days. Participants were paid $\$ 3.00$ per hour plus a bonus of $\$ 1.00$ per hour for those who completed the four-day test period.

\section{Apparatus}

Energy cost information was presented on a panel housing six LED (light emitting diode) displays, as shown in Figure 1. A computer generated the displayed dollar and cent values which were calculated from the energy usage for a sample of appliances. Scenarios were developed representing various amounts of energy usage for both summer and winter seasons and for electric homes and gas and electric homes. Appendix A provides cumulative, instantaneous, and projected energy cost values associated with summer and winter usage of each of the appliances included in the study. Cumulative and projected values were based on average appliance usage, Whereas instantaneous values were derived from kilowatt hour energy consumption. Appendix A also includes literature sources for the energy-cost values. 


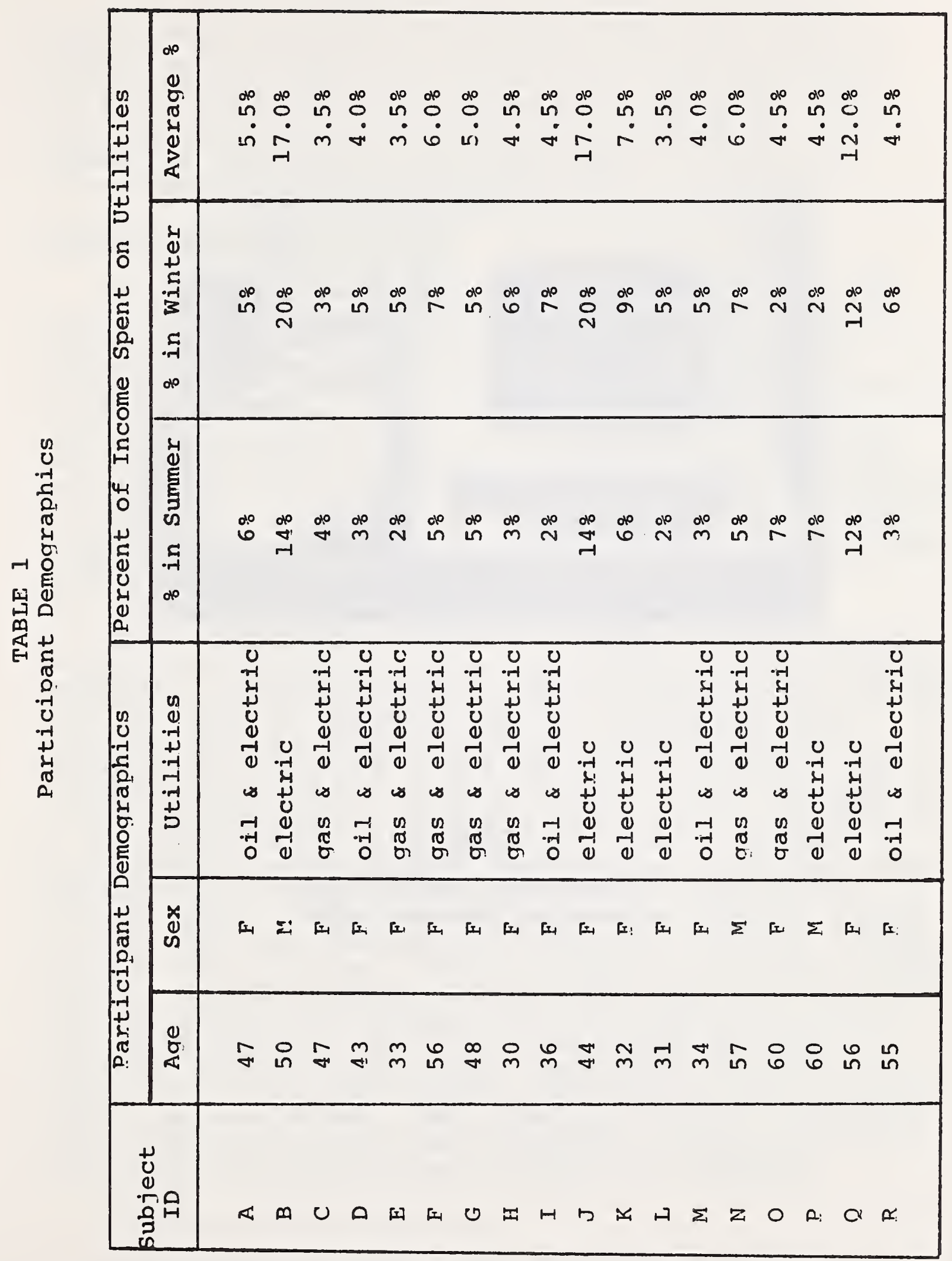




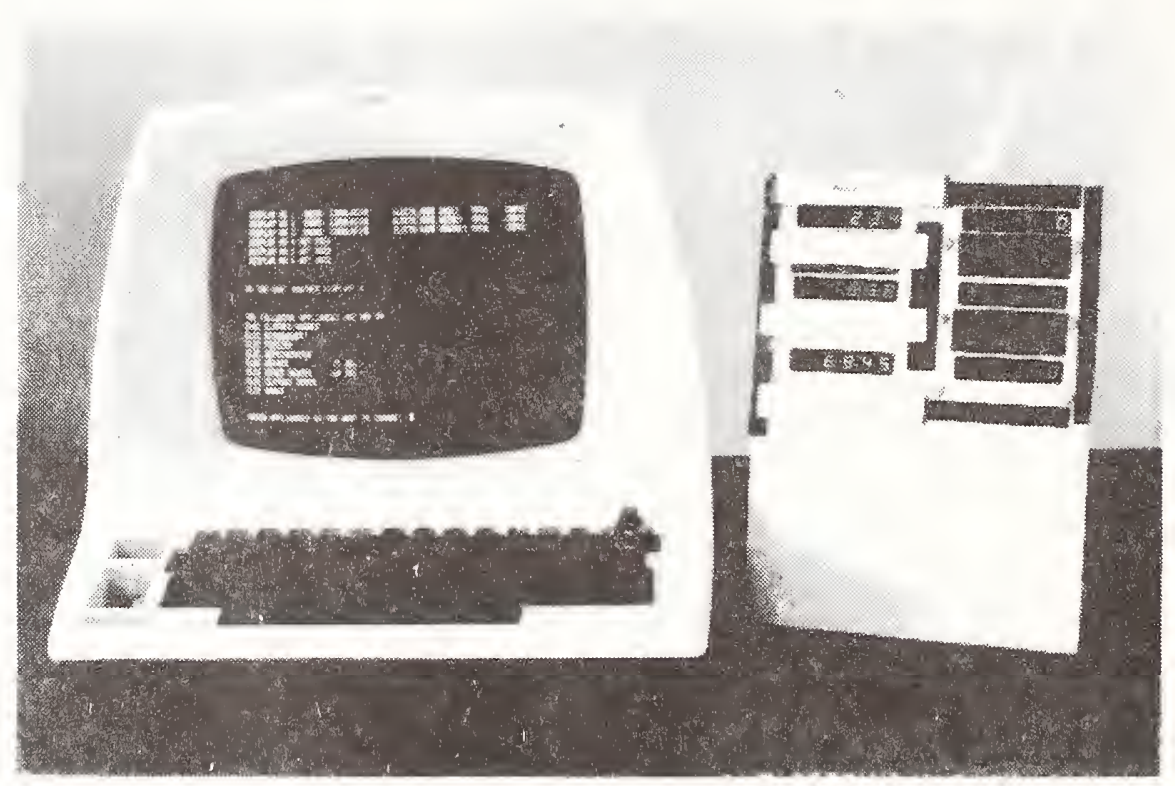

FIGURE I

Interactive Terminal and

Feedback Display Panel 
Also shown in Figure 1 is an interactive terminal that allowed participants to simulate appliance usage by turning the appliances included in the sample on or off. The participants were able to study the displayed values and to note changes in the energy cost information as a result of their simulated energy-using activities. Interviews with participants were aduio-taped to facilitate later data compilation.

Experimental Tasks

At the present stage of research concerning the most effective type of energy cost feedback, all the relevant goals and hypotheses have not yet been identified, and consequently the appropriate measures to make have not been specified. Therefore, individual interviewing techniques similar to those used in focus group interviewing were used. Interviewing techniques were employed because they have been previously shown to be useful in guiding policy decisions and serve as a way to confirm thoughts and suspicions, to suggest new ideas and hypotheses, and to identify appropriate consumer language. The general purpose of the interviews was to identify the pertinent issues and concerns regarding energy cost feedback.

Each subject participated in a series of conditions designed to illustrate the various feedback types and obtain participant responses to each. These conditions were designed such that for each feedback type, the participant was presented with a scenario of appliance usage which was displayed on the screen of the interactive terminal. The scenarios represented average or typical energy consumption of several appliances. The participant was able to look at the screen to see which appliances were on and what the thermostat settings were, and then note the cost values displayed on the LED display panel for that particular feedback type. The participant could then simulate changes in appliance usage through the interactive terminal. These changes would, in turn, result in changes in the cost values shown on the LED display. Through this iterative process, each participant was educated as to (1) the kinds of values they could expect to see if they had a feedback meter in their own home that was actually connected to their energy supply and (2) how their energy usage behavior would affect those displayed values. The experimenter used a discussion guide to help the participants discuss a wide variety of issues related to each type of energy cost feedback.

On Day 1, participants:

- completed an energy usage questionnaire designed to determine their attitudes and awareness toward energy usage and conservation, 
o were familiarized with the definitions of and differences between the three types of energy feedback being examined; and

o were briefed on the tasks to be completed during the remainder of their participation, including a demonstration of the apparatus.

The interview materials used in each of the above Day 1 tasks are presented in Appendices B, C, and D.

On Days 2 and 3, participants were shown each type of energy-cost feedback. After exposure to each of the feedback types, participants were interviewed to determine their reactions to the feedback type, their impressions of the meaningfulness and usability of the displayed values, their preferences for time periods, and their preferences for total versus separate energy cost figures. The reader should refer to Appendices $E, F$, and $G$ for the interview guide associated with each feedback type.

Table 2 shows the feedback conditions to which each participant was exposed. When examining these various combinations, participants were allowed to choose whether they would view summer appliance usage values or winter appliance usage values.

Participants who lived in all-electric homes viewed energy cost values for electric appliances only, and those participants with gas-and-electric or oil-and-electric homes were shown energy costs for a combination of electric and gas appliances. This assignment to conditions was employed because it was felt that all-electric home owners would be merely speculating about whether they would want a total display or separate displays of energy sources. On the other hand, those participants with two-energy-source homes would be better able to make a judgment as to whether they would want their utility costs shown as combined or separate costs.

The sample size ( $N=18)$ allowed for presentation of feedback type (cumulative, instantaneous, and projected) to be counter-balanced so that any order effects present would not bias the results. Each participant was exposed to the time periods in an order ascending from the shortest time period to the longest. For subjects with gas and electric or oil and electric homes, total energy costs were presented first, followed by gas and electric costs separately. 


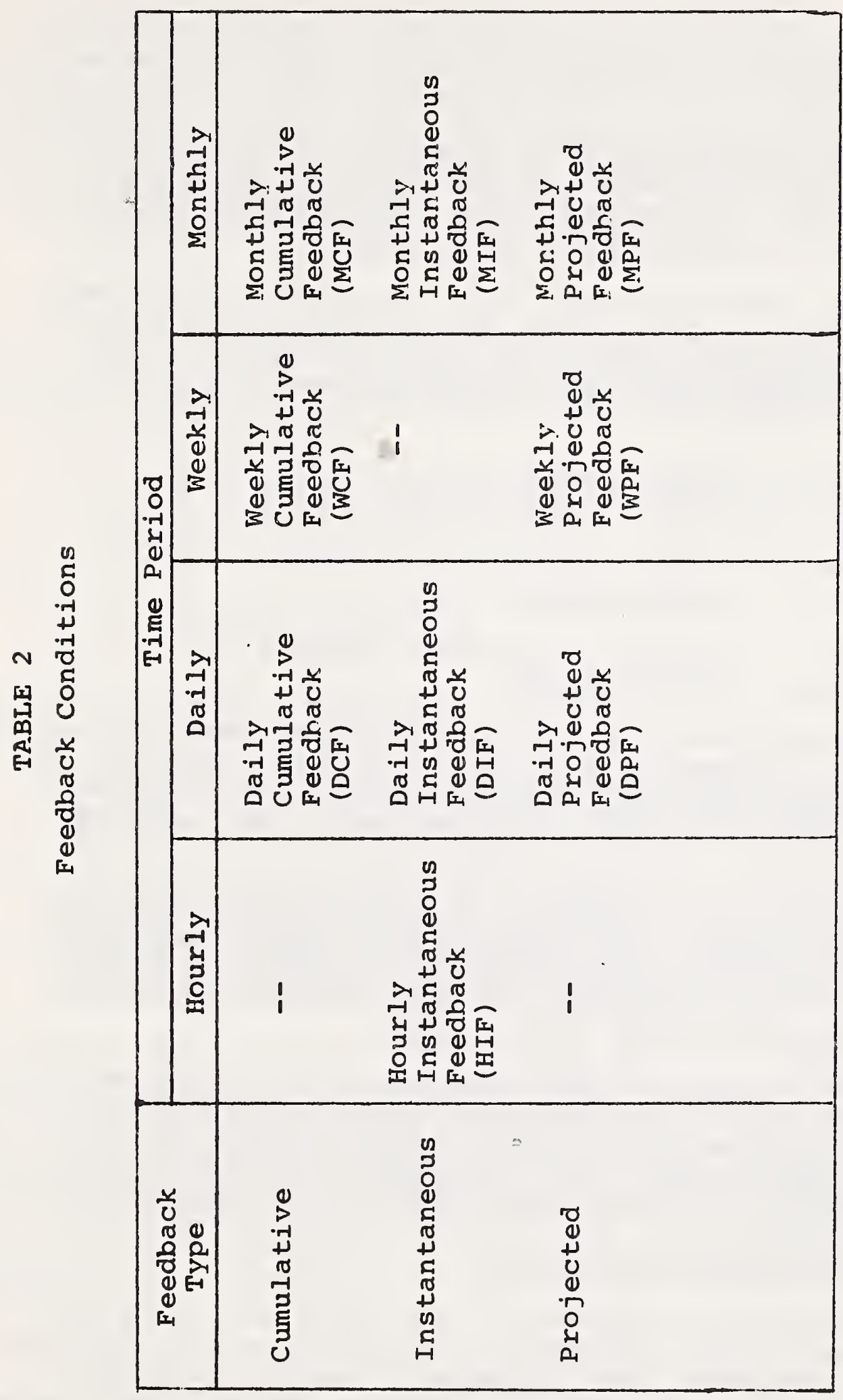


On the third day of participation, subjects were also asked to design their preferred energy cost feedback meter. If the design involved more than three displays, the participant was then asked to limit the meter to three displays. Interviewing was conducted to determine why each participant preferred that combination of information displays on a feedback meter. Appendix $\mathrm{H}$ shows the interview guide used to discuss the participant's meter design.

On the fourth and final day, participants were shown an energy-cost feedback meter which was based on input from DOE's Consumer Motivation Branch personnel. The prototype incorporated three displays providing the following types of information:

$$
\begin{gathered}
\text { Display } 1 \text { - Hourly Instantaneous feedback on } \\
\text { energy usage; } \\
\text { Display 2 - Daily Cumulative feedback on energy } \\
\text { usage; and, } \\
\text { Display } 3 \text { - Monthly Cumulative feedback on } \\
\text { energy usage. }
\end{gathered}
$$

For each of the displays, participants were queried as to whether the information displayed should be presented as a total energy figure or whether energy usage should be broken down into its two energy sources, i.e., gas and electric.

Additionally, for Display 2, participants discussed whether the previous day's energy cost should be stored and, if so, for how long it should be stored. Appendix I shows the questions which the participants were asked regarding the prototype meter design.

A final interview (see Appendix J) was conducted to assess participant's knowledge of energy cost feedback and their preferences for energy cost information. In addition, participants were asked what instructional materials should accompany the proposed meters for consumer use.

\section{Participant Response Categories}

Participants' responses to the types of energy-cost feedback were coded to summarize the information obtained through interviews. The following response categories represent issues and reactions revealed during interviewing: 
- Understanding the purpose of each feedback display--do the participants understand the nature of the information displayed? Do the participants have reservations about the purpose?

- Understanding how the feedback information was derived--do the participants understand how the displayed values were determined? Do the participants feel the derivation is clear and accurate? Do the participants like the derivation?

- Usability--how do participants say they would or could use each type of feedback? The specific uses which the participants mentioned most often are listed below:

- for budget management--would participants compare the displayed values to their individual utility and/or household budgets?

- for determining energy consumption cost of individual appliances,

- for identification and comparison of differing patterns of energy use

- Meaningfulness--do the participants feel that the feedback type has meaning to them? Does the feedback information have face validity? Is the information accurate and realistic? Meaningfulness is related to how and if a feedback type would be used by consumers to help conserve energy and the amount of instructional information which must accompany the feedback meter for residential use.

Notes taken during interviews as well as recordings of daily sessions were reviewed to assess participants" answers to questions and opinions about feedback. Comments were classified as being positive, negative, or non-committal (where a non-committal comment refers to no comment, a neutral comment, or a comment too vague to categorize). Only those comments which were definite affirmations or negations were classified as such, with other responses assessed as non-committal. 
The findings presented below are based on a small sample. The sample was not intended to be statistically representative of the general population and hence quantitative projections should not be made. It is nevertheless believed that the attitudes expressed are illustrative of those that exist in the population at large.

\section{Awareness-Attitudes Toward Energy Conservation}

A questionnaire was used to assess participant's awareness of and attitudes toward energy conservation prior to learning about energy cost feedback. Three out of eighteen participants were able to accurately report the portion of their income spent on utilities. Only one person reported that she knew how the utility company computed charges for energy use. All participants reported that they actively do or have done things to conserve energy in the home, with one person reporting that she occasionally checked her electricity meter.

When asked whether additional energy conservation information would be beneficial, seventeen of the participants reported that some sort of additional information would help them conserve energy in the home. Specifically, two people wanted information on home insulation; eleven people wanted information on energy used by various appliances; two people wanted general information on energy conservation; two wanted to know the amount of energy they used per day or for some defined time period; and, one person wanted to know during what times energy is least expensive. This energy conservation information could be provided through a variety of educational programs or materials as well as by means of a feedback device.

\section{Response Categories}

Participants' responses to cumulative, instantaneous, and projected feedback and the DOE Prototype meter are summarized in this section. Responses are presented for each response category separately with data presented as the frequency and proportion of responses that are positive, negative, and non-committed for each response category.

UNDERSTANDABILITY OF THE PURPOSE-Table 3 presents the numbers and proportions of positive, negative, and non-committed responses for each time period of cumulative, instantaneous, and projected feedback and the DOE prototype 


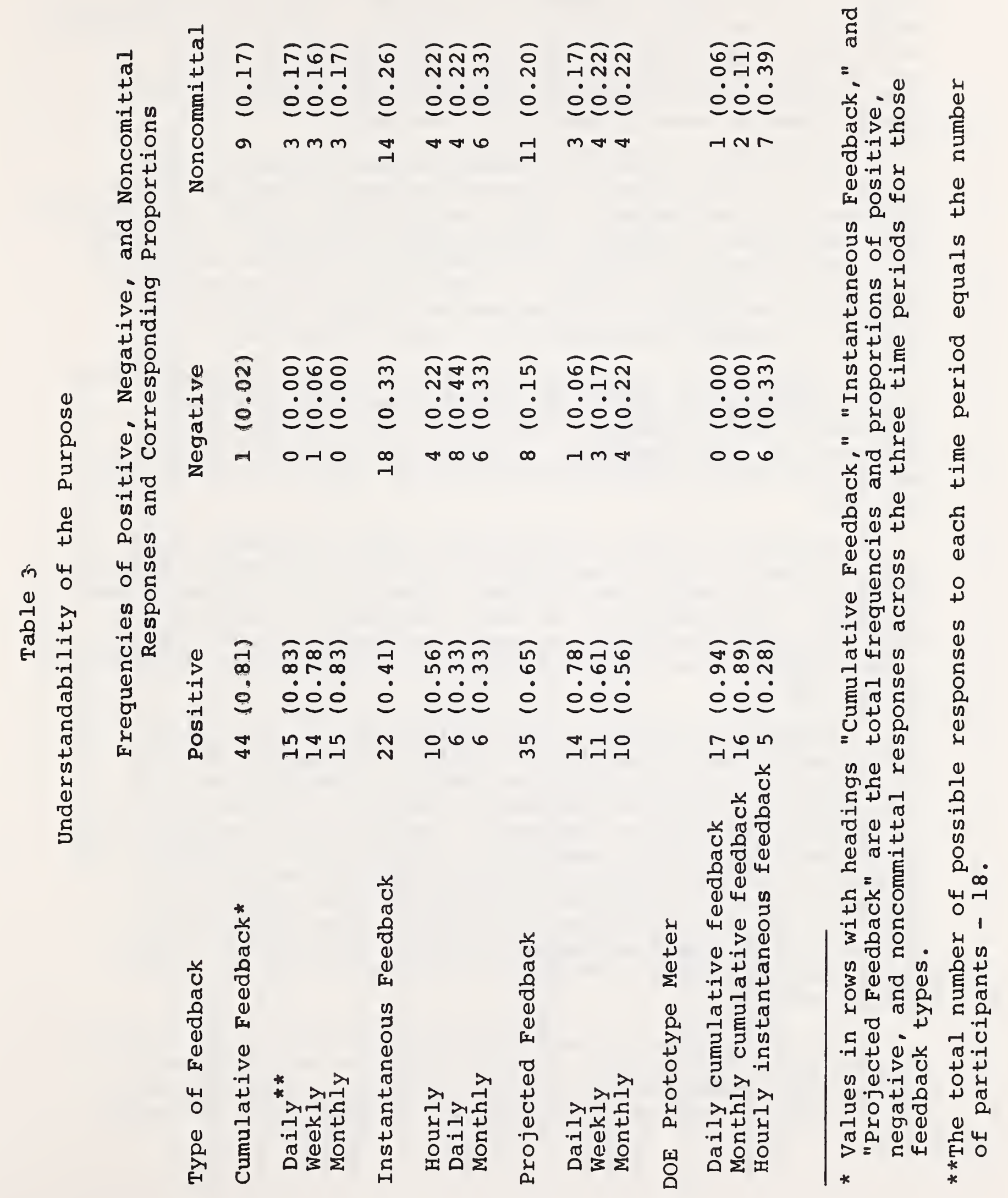


meter. Predominantly favorable responses were received concerning the understandability of the purpose of daily, weekly, and monthly cumulative feedback. Cumulative feedback, as a record of actual energy use, appears to be simple and easily understood by the consumers sampled. Only one participant reported having problems with understanding the purpose of weekly cumulative feedback.

of the three types of instantaneous feedback, the proportion of positive responses for hourly instantaneous feedback is the largest. More positive than negative responses were made only to hourly instantaneous feedback. Generally, The participants felt that the purpose of estimating energy cost from a current sample of energy use was unclear when trying to estimate to a time period of more than one hour since the energy use sampled can vary considerably.

A majority of responses concerning the understandability of the purpose of projected feedback were favorable. Generally, the purpose of all three types of projected feedback is understandable, with daily projected feedback being more easily understood than the other projected time periods.

Responses to the DOE prototype meter indicated that the purpose of daily cumulative feedback and monthly cumulative feedback were more understandable than hourly instantaneous feedback. The responses to daily cumulative feedback and monthly cumulative feedback were overwhelmingly positive, with hourly instantaneous feedback receiving fewer favorable responses.

UNDERSTANDABILITY OF THE DERIVATION--As indicated in Table 4 , the proportion of positive responses across the three types of cumulative feedback combined was 0.57 , with only one negative response reported to the derivation of monthly cumulative feedback. The problem reported in understanding monthly cumulative feedback was in remembering that the value is derived from continuous cumulation of energy cost for an entire month--a problem that may have been due to the experimental setting. The derivation of cumulative feedback as energy actually used seems to be well understood and a desirable characteristic of energy cost feedback.

The derivation of instantaneous feedback using current energy usage to estimate to some future time period was not easily understood by the participants. The responses to the derivation of instantaneous feedback were primarily 


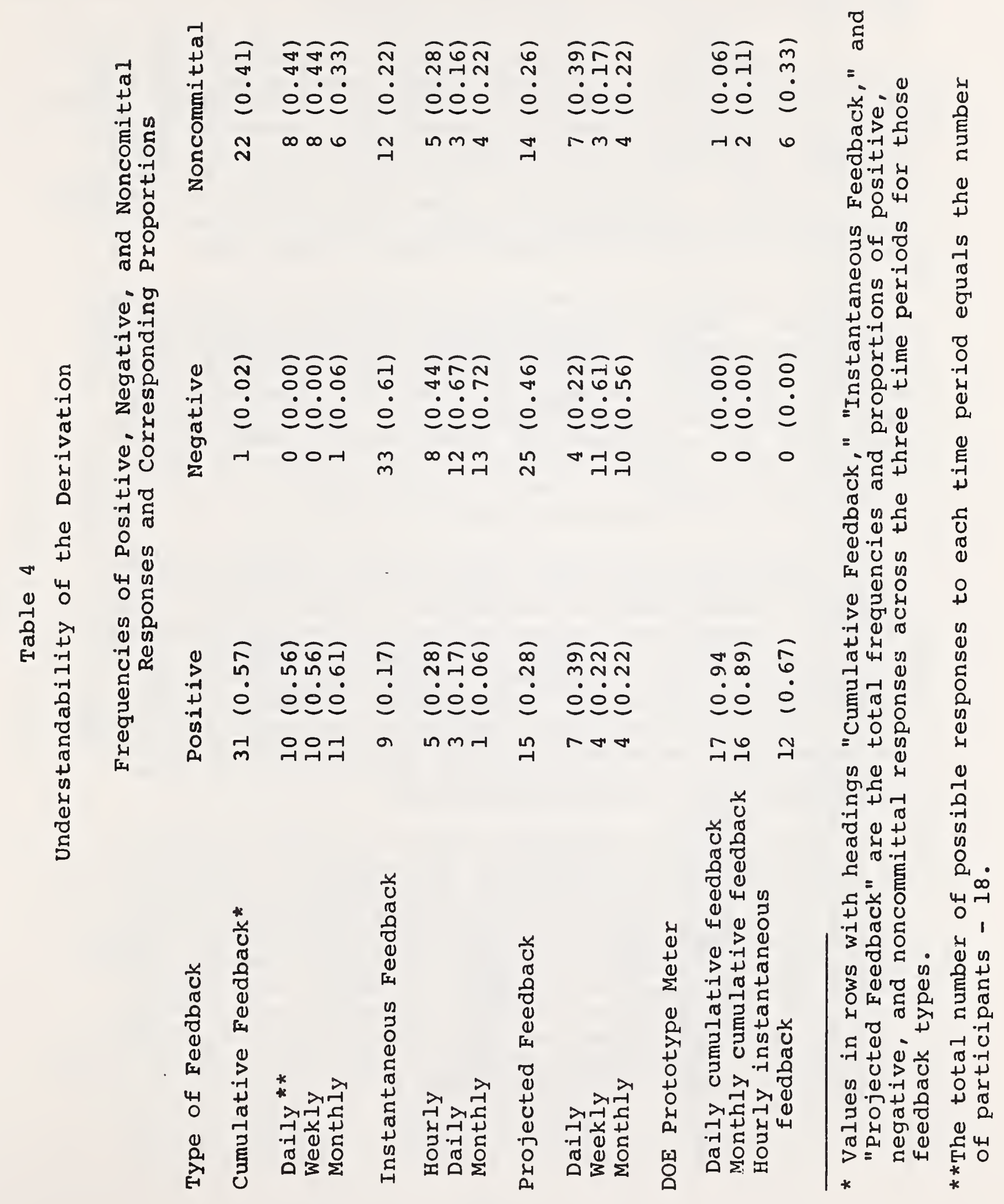


negative. Of the three instantaneous time periods, the derivation of hourly instantaneous feedback was best understood but received only five positive responses.

The assumption that the instantaneous values displayed reflect energy cost if energy is used continuously at its present rate was regarded as invalid by the consumers sampled. Daily instantaneous feedback and monthly instantaneous feedback exacerbate this problem since they assume that energy is used continuously at the same rate for an entire day or month. A longer sample time was considered desirable for deriving instantaneous feedback values in order to get a more accurate estimate of actual energy usage.

The derivation of projected feedback received mixed reactions. The derivation of daily projected feedback was considered the most understandable with more positive than negative responses. Both weekly projected feedback and monthly projected feedback received more than twice as many negative as positive responses. Some participants felt that projected feedback should not be based on the previous day's energy cost but on some average of days (e.g., the average of a week's energy cost) to reduce varia variability and facilitate budget estimates.

Responses to the derivation of the displays included in the DOE prototype meter indicated that participants tended to understand the derivation of each of the three feedback types. When the responses to the understandability of the derivation of hourly instantaneous feedback (0.67) are compared to the responses to the understandability of the purpose of hourly instantaneous feedback (0.28) in the DOE prototype meter display, a discrepancy is noted. It seems that the majority of the participants understand how hourly instantaneous feedback was derived but some had difficulty in understanding why.

USABIIITY FOR BUDGETING--Table 5 presents responses to the usability for budgeting of each type of feedback. The use of cumulative feedback for budgeting energy expenditures received a total of 37 positive responses. Daily cumulative feedback and monthly cumulative feedback were most favorably viewed for budgeting considerations. While there were no negative responses to weekly cumulative feedback, responses were evenly divided between positive responses and non-committed responses, meaning that half of the participants did not mention the usefulness of weekly cumulative feedback for budgeting. 


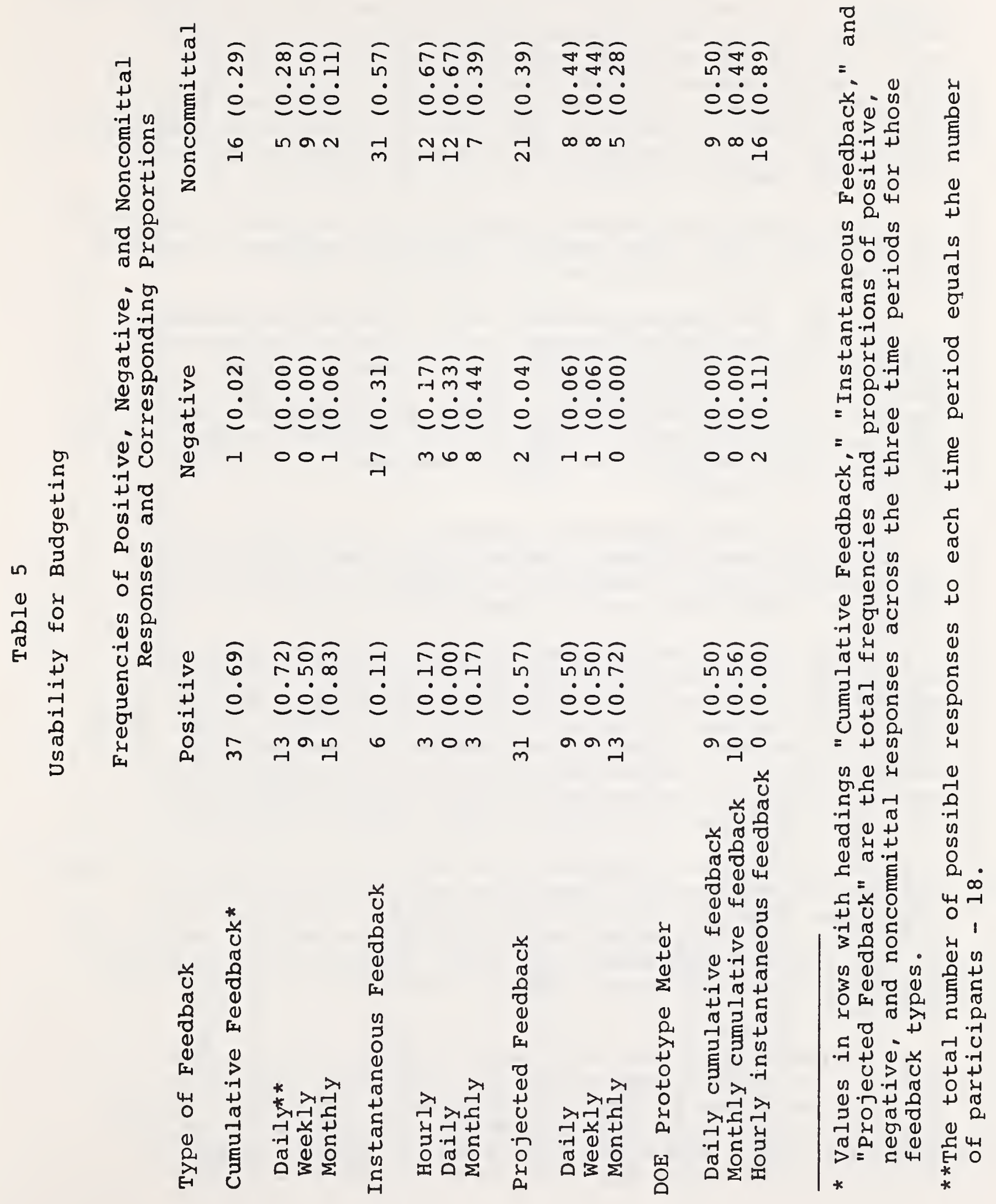


Overall, study participants did not consider instantaneous feedback to be very useful in helping them budget energy expenditures. Hourly instantaneous feedback received as many positive as negative responses regarding this use. Daily instantaneous feedback and monthly instantaneous feedback received more negative than positive responses with the participants indicating that the estimates were unrealistic since they would be very high if several high-energy-using appliances happened to be on at the same instant.

All types of projected feedback were favorably considered for budgetary use, with monthly projected feedback receiving the most favorable reaction for budgetary use.

In the DOE prototype meter daily cumulative feedback and monthly cumulative feedback were both considered more favorably than hourly instantaneous feedback for use in monitoring the energy budget. Hourly instantaneous feedback received no positive responses and a large proportion of non-committed responses. Hourly instantaneous feedback seems to have little utility for budget management in the opinion of the participants.

USABILITY FOR MONITORING INDIVIDUAL APPLIANCE USE-A summary of participants' responses to the usability of the various types of energy-cost feedback for monitoring individual appliance use are presented in Table 6 .

Daily cumulative feedback was the preferred type of cumulative feedback for monitoring individual appliance usage, while the weekly cumulative feedback and monthly cumulative feedback time periods were considered less useful for this purpose. This use of cumulative feedback was considered to be a short-term use; i.e., consumers would not need to continue monitoring individual appliances once they learned about the cost of using various appliances.

More positive responses were made to the use of instantaneous feedback to monitor the energy use of various individual appliances than any other possible uses of instantaneous feedback. Hourly instantaneous feedback received a majority of the positive responses with daily instantaneous feedback and monthly instantaneous feedback receiving fewer positive responses.

It should be noted that using hourly instantaneous feedback to monitor energy use of individual appliances would probably be a temporary behavior only. Participants noted that once they had learned the cost of using various appliances they would no longer need to monitor feedback information for this purpose. Participants also noted 


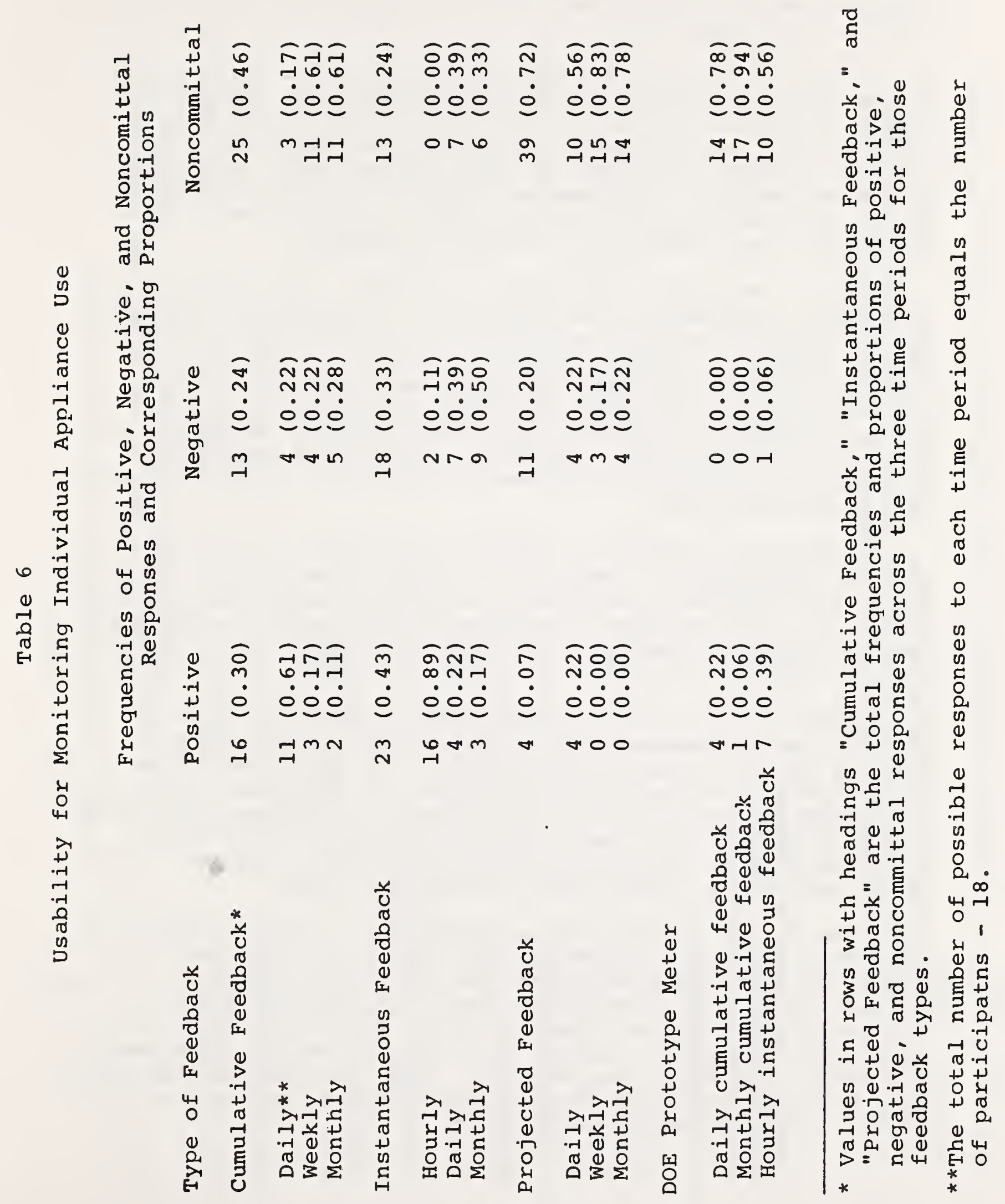


that they could obtain this information from sources other than an energy feedback device (e.g. published conservation brochures and pamphlets).

Overall, projected feedback does not lend itself well to use for estimating cost of using individual appliances. Since projected feedback values are estimates based on a day's total energy cost, it has limited usefulness for monitoring small portions of total energy use. Only daily projected feedback received any positive comments with all three types of projected feedback receiving more noncommitted than positive or negative responses.

When viewing the DOE prototype meter, five participants favorably responded to the usability of cumulative feedback for determining energy consumption of various appliances, but the majority of responses to cumulative feedback's usability for monitoring individual appliance use were non-committal. Individual appliance monitoring may be the most valuable use of hourly instantaneous feedback, as seven participants made positive responses to this use of hourly instantaneous feedback, while only one participant responded negatively.

COMPARING PATTERNS OF ENERGY USE--Table 7 contains data on participants' responses to using cumulative, instantaneous and projected feedback to compare patterns of energy use (e.g. from one week to another or one season to another). For all types of feedback, more non-committed than committed responses were made.

Overall, this use of cumulative feedback received 16 positive responses. The only negative response was made to monthly cumulative feedback. Of the three types of cumulative feedback, daily cumulative feedback was preferred for comparing patterns of energy use as it allowed comparison of daily activities. Participants felt that this use of daily cumulative feedback could be aided by a device which would save the previous day's cumulative value.

The use of instantaneous feedback to compare patterns of energy use received few overall positive responses. Hourly instantaneous feedback was the only type of instantaneous feedback which received any positive responses for use in comparing patterns of energy use. Instantaneous feedback is designed to update energy readings and make new estimates of energy cost every few seconds. Such variability apparently does not lend itself to comparisons among long time periods, such as between months or seasons. 


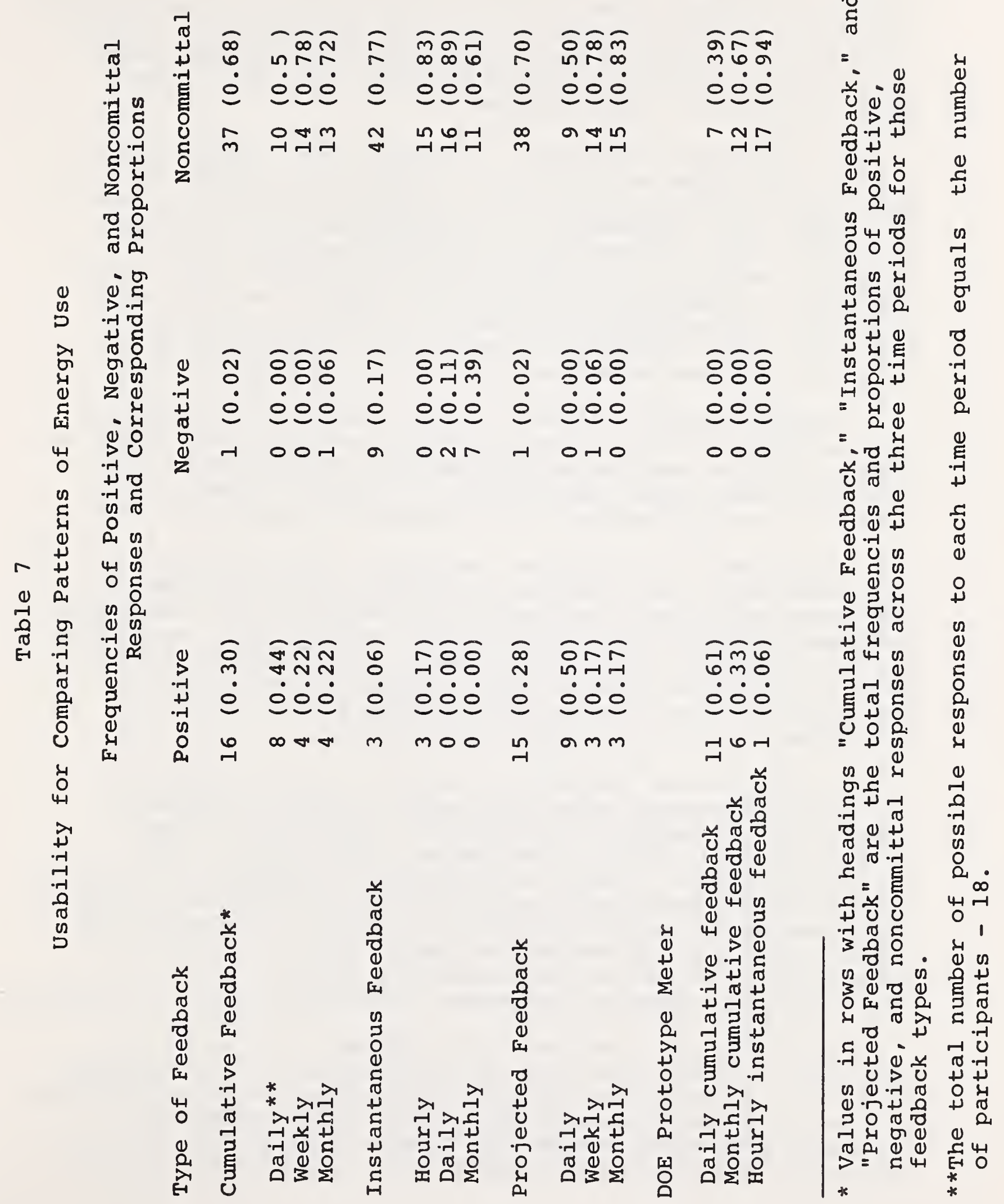


The use of projected feedback to compare patterns of energy use received 15 positive responses. Of the three projected feedback time periods, daily projected feedback was considered the most usable for comparing patterns of energy use with nine positive responses, while weekly projected feedback and monthly projected feedback were both viewed less favorably for this purpose.

An inspection of Table 7 indicates that, when viewing the DOE prototype meter, eleven of the participants said they could use daily cumulative feedback to monitor patterns of energy use, compared to six participants who indicated that they could use monthly cumulative feedback for this purpose. Only one of 18 participants indicated they could use hourly instantaneous feedback to monitor energy use patterns. Consequently, of the three DOE prototype meter displays, daily cumulative feedback was considered most favorably for use in comparing patterns of energy use.

MEANINGFULNESS--Table 8 presents data on the meaningfulness of cumulative, instantaneous, and projected feedback. Both cumulative and projected feedback received more noncommitted than committed responses, whereas instantaneous feedback received predominantly negative responses.

Responses to cumulative feedback's meaningfulness indicated that daily cumulative feedback was considered most meaningful, monthly cumulative feedback less meaningful and weekly cumulative feedback least meaningful. Generally, the participants liked seeing their cost of energy as they used it and found a daily value easiest to work with. They felt that daily cumulative feedback could be used to estimate costs for longer time periods.

Instantaneous feedback in general was not regarded as highly meaningful with only seven positive responses compared to 40 negative responses. Participants found instantaneous feedback a new concept that did not seem entirely accurate. Daily instantaneous feedback and monthly instantaneous feedback received a large proportion of negative responses which suggests that these forms of instantaneous feedback had little meaning for participants. Hourly instantaneous feedback was considered somewhat more understandable, but negative responses outweighed positive responses.

Five positive responses as compared to 20 negative responses reflects the lack of meaningfulness of projected feedback. Overall, participants felt that projected feedback was not considered meaningful because daily variations in energy use would not be accounted for accurately in projected energy cost estimates. That is, if the previous 


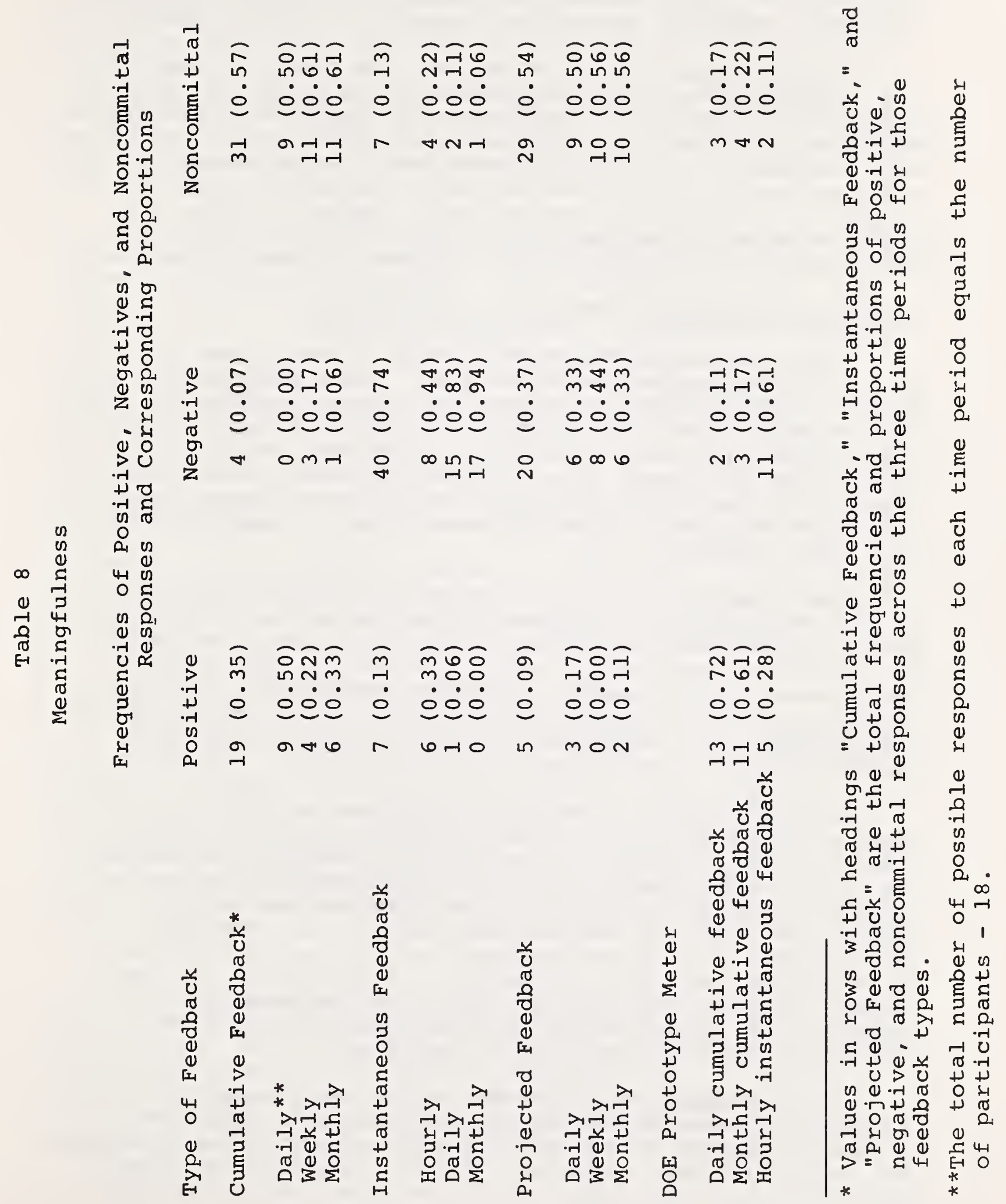


day's activities required an inordinately high use of energy (as on house cleaning day), projected values would not represent realistic estimates of weekly or monthly costs.

Of the values displayed for the DOE prototype meter, the meaningfulness of daily cumulative feedback and monthly cumulative feedback received larger proportions of positive responses than hourly instantaneous feedback. When compared with responses to hourly instantaneous feedback when it was presented alone and not as part of the prototype meter, it appears that hourly instantaneous feedback values are highly meaningful neither when they are shown alone nor when presented in combination with other types of feedback.

Cumulative Feedback Summary and Conclusions

Daily cumulative feedback is easily understood in terms of its purpose and derivation. All committed reactions to its meaningfulness were positive. Daily cumulative feedback is more likely to be used to obtain information on energy consumption of individual appliances and for comparing patterns of appliance usage than either weekly cumulative feedback or monthly cumulative feedback. All committed responses regarding budgetary uses of daily cumulative feedback were positive.

The drawbacks of daily cumulative feedback include 1) the inconvenience of checking the values each day, 2) the record keeping required to determine energy consumption of individual appliances, and 3 ) the possibility that if daily cumulative feedback is used to monitor effects of changing appliance usage individually, the relatively small value changes may decrease the motivation to conserve on usage of small energy users.

Weekly cumulative feedback's purpose and derivation appear understandable. Based on positive responses, it does not seem as likely to be used for budgetary concerns as either daily cumulative feedback or monthly cumulative feedback. Both weekly cumulative feedback and monthly cumulative feedback were not responded to as favorably as was daily cumulative feedback for gaining information on individual appliance consumption and patterns of energy usage. In addition, weekly cumulative feedback does not appear to be as meaningful as either daily cumulative feedback or monthly cumulative feedback.

Daily cumulative feedback and monthly cumulative feedback received relatively large numbers of positive responses regarding understandability of derivation, purpose, and budgetary uses. However, the participants' responses indicated that they would not be as likely to use monthly 
cumulative feedback as they would use daily cumulative feedback to monitor individual appliance energy consumption or compare patterns of energy usage. In addition, more positive responses were made to the meaningfulness of daily cumulative feedback than to monthly cumulative feedback. According to participants, the main benefit of monthly cumulative feedback is its usefulness in budgetary matters and the corresponding likelihood that consumers will decrease energy consumption if their cost of usage is exceeding the utility allocation in their budget.

Across the six response categories, daily cumulative feedback and monthly cumulative feedback are the most preferred forms of cumulative feedback. The difference in how they would be used concerns their usability for monitoring the energy cost of individual appliances. Eleven participants said they could use daily cumulative feedback for this purpose, as compared to two participants who said they could use monthly cumulative feedback in this manner. Daily cumulative feedback requires record keeping if consumers are to use it to determine how their energy cost to-date compares to their utility budget. Its benefit is that it may encourage consumers to attend to energy conservation on a daily basis. Monthly cumulative feedback does not require record keeping in order to compare energy cost to-date to the utility budget. In addition, the increasingly larger numbers displayed by monthly cumulative feedback may make consumers more aware of the ultimate consequence of their behavior than would daily cumulative feedback.

Instantaneous Feedback Summary and Conclusions

Although primarily positive responses were made to the purpose of hourly instantaneous feedback, hourly instantaneous feedback received fewer positive than negative responses regarding its derivation and meaningfulness. Only three positive reactions were made to using hourly instantaneous feedback for budgetary purposes and for comparing patterns of energy use. The main advantage of hourly instantaneous feedback is its perceived usefulness in determining the relative energy cost of individual appliances.

More negative than positive responses were made to daily instantaneous feedback for each of the six response categories. Participants saw little utility of daily instantaneous feedback and overwhelmingly felt that it was not providing meaningful information. Monthly instantaneous feedback suffered the same adverse reactions as did daily instantaneous feedback. The difference in reactions to 
monthly instantaneous feedback and daily instantaneous feedback is one of degree, with monthly instantaneous feedback generally receiving more negative and fewer positive reactions.

In summary, hourly instantaneous feedback was generally the preferred form of instantaneous feedback, while daily instantaneous feedback and monthly instantaneous feedback were viewed by the participants as having little or no utility. Problems were encountered with hourly instantaneous feedback however. These included:

1) difficulty in grasping the underlying assumption of continuous appliance operation for one hour;

2) the inaccuracy of the values displayed with regard to actual cost due to the disparity between the assumption of continuous operation and how long appliances are actually used;

3) its limited utility in budget matters; and,

4) its questionable appropriateness for providing individual appliance energy consumption information.

Projected Feedback Summary and Conclusions

Daily projected feedback received the largest number of positive responses across response categories among the three forms of projected feedback. One notable exception is usability in budgetary matters for which monthly projected feedback received more positive responses. Participants' responses indicated that they felt that daily projected feedback provides the same information as saving yesterday's daily cumulative feedback. The general reaction to saving that figure was positive, and participants felt that yesterday's cost information should be provided on a feedback meter if the cost of doing so is not substantial.

Primarily positive responses were made to weekly projected feedback's purpose and usability for budgeting, with a small proportion of positive responses made to its derivation and usability for comparing patterns of energy use. No positive reactions were made to using weekly projected feedback for the identification of individual appliance energy usage cost. The main drawback of weekly projected feedback is its lack of meaningfulness. 
As with the other forms of projected feedback, participants did not view monthly projected feedback as being very meaningful. Participants made more positive responses to using monthly projected feedback for budgetary purposes than either daily projected feedback or weekly projected feedback. The large proportion of non-committal responses to the use of monthly projected feedback for comparing patterns of energy use suggests that this use was not very obvious to the participants. No positive responses were made to using monthly projected feedback for monitoring individual appliance use. As with daily projected feedback and weekly projected feedback, participants generally responded positively to understanding the purpose of monthly cumulative feedback but less favorably to understanding the derivation.

In summary, daily projected feedback was the preferred type of projected feedback. However, monthly projected feedback was responded to more favorably for its usability in budgeting. Generally, the participants seemed to want to use feedback to either help them budget or determine the effectiveness of various energy conservation measures. Apparently, projected feedback as it has been derived does not provide the desired information in an easily understood and meaningful way. Perhaps a form of projected feedback that would be more meaningful and usable would be one which uses the monthly cumulative cost to date and projects that value to the end of the month. That is, if the cumulative cost at the end of the first week of the month was $\$ 10.00$, then the projected monthly cost would be $\$ 10.00 \mathrm{x} 4$ weeks, or $\$ 40.00$.

\section{DOE Prototype Meter Summary and Conclusions}

Based on participants' responses to the DOE prototype meter, daily cumulative feedback and monthly cumulative feedback fare well; in all cases the positive comments outweigh the negative comments. For all the response categories there were relatively few or no negative comments directed at cumulative feedback.

On the other hand, the opposite seems to be true for hourly instantaneous feedback. The participants had difficulty grasping the meaning of the hourly instantaneous feedback information. Although they understood how hourly instantaneous feedback was derived, they had problems understanding its purpose. The participants expressed little use for hourly instantaneous feedback for monitoring budgets or patterns of energy use. Its strongest positive point is that hourly instantaneous feedback was considered useful 
for monitoring individual appliance energy use by more participants than daily cumulative feedback and monthly cumulative feedback combined. However, this still represents less than a majority opinion--seven of 18 participants. In addition, the prevailing opinion among the participants was that hourly instantaneous feedback would either only be used for the first couple of weeks, or that it was not accurate and yielded unrealistic information and would consequently not be used at all.

\section{Participants' Own Designs}

Participants were asked to choose the particular combination of feedback information that they would like to have for their own use. If a participant chose more than three different kinds of information displays, they were asked to limit their choices to only three displays.

Sixteen out of 18 participants chose to include some form of cumulative feedback for their own use. Of these, daily cumulative feedback was the preferred form of cumulative feedback, being chosen by six participants. Four participants chose weekly cumulative feedback while two chose monthly cumulative feedback. Two participants chose daily cumulative feedback and monthly cumulative feedback in combination, while one person preferred the daily cumulative feedback and weekly cumulative feedback combination. One person wanted all three types of cumulative feedback included in the feedback meter design.

Six out of 18 participants chose to include some form of instantaneous feedback for their own use. Of those consumers who expressed a preference for instantaneous feedback, five chose hourly instantaneous feedback while one person preferred daily instantaneous feedback.

Three out of 18 participants chose to include some form of projected feedback in their own feedback meter design. Of these, one person preferred daily projected feedback, one preferred monthly projected feedback, and one preferred daily and weekly projected feedback in combination.

All participants having two energy sources in their home (e.g., oil and electric or gas and electric homes) expressed a preference for having feedback presented as two separate values rather than a total cost. Participants felt that such separate cost displays would help them better determine which energy source (e.g., gas or electric) was accounting for the larger portion of the overall energy cost. This knowledge would in turn help the consumer plan future conservation measures and evaluate previous measures. 
Answers to a final written questionnaire verified that cumulative feedback was the overall preferred form (for 16 participants) of feedback information, with the remaining two participants preferred instantaneous feedback.

\section{DISCUSSION}

$\underline{\text { Related Research and Recommendations }}$

The results of the present study lend support to previous work done in the area of feedback. Several hypotheses have been suggested to explain why feedback facilitates residential energy conservation and what characteristics effective feedback should have. Some of the hypotheses and their relevance to the present study are discussed below.

Participants' answers to questions designed to assess attitudes toward and awareness of energy conservation revealed that consumers are motivated to conserve energy but need information to teach them about energy consumption of appliances and conservation behaviors leading to greater energy savings. According to the human factors approach, "Feedback teaches people how to make appropriate conservation responses" (Seligman, 1978). Seligman contends that this explanation of feedback as a form of trial and error learning does not apply in energy conservation situations since homeowners can learn about successful techniques for reducing energy consumption from sources other than by feedback. Consequently, Seligman maintains that when homeowners already know conservation measures, feedback does not facilitate energy conservation through teaching new, skilled responses. Rather, it keeps the idea of conservation salient and it frequently shows the consumer how he is doing in achieving some goal.

In view of the fact that consumers can learn about energy conservation measures from a variety of sources, the use of feedback as a method of determining energy consumption of various appliances was considered nonessential by participants. Participants reported that their reliance on a feedback display to provide information about effective conservation measures would be short-lived. That is, once they had this information they felt that they would no longer need to rely on a feedback device for this information.

This reaction by the participants has particular relevance to instantaneous feedback. According to study participants, the main advantage of hourly instantaneous feedback is its use in determining the energy cost of individual appliances. 
This use of instantaneous feedback may have diminishing returns since there is no need to continuously monitor the energy consumption of various appliances once this information has been learned.

The problem participants had with instantaneous feedback is that it is not based on actual use of energy and as an estimate has limited information value. It is recommended that a careful analysis be performed regarding the appropriateness of providing instantaneous feedback in a feedback meter since consumers reported some difficulty in understanding the purpose and derivation of instantaneous feedback.

Baldwin (1977) suggests several functional characteristics of effective feedback. First, feedback should always be expressed in the most meaningful units possible. The present study used feedback values expressed as dollars and cents. All participants found this to be a meaningful measure of energy consumption. Participants were overwhelmingly in favor of the meter presenting gas and electric costs as separate values. As a result it is recommended that feedback be geared to the needs of the consumer such that consumers receive feedback segmented into the energy sources appropriate for their homes.

Second, Baldwin recommends that there be a clear understanding of the purposes for which feedback information will be used by the household. Participants in the present study indicated that they would use energy cost feedback primarily for purposes of budgeting, determining energy costs associated with given patterns of energy use, and determining energy costs of various appliances. These intended uses of feedback dictate that feedback should be provided in a form that allows monitoring and comparison of actual energy use. The usefulness of cumulative feedback for budgetary purposes as well as for determining energy costs associated with given patterns of energy use combines two desirable features of feedback. For determining energy costs of various appliances, some participants suggested an appliance metering device that could be connected to one appliance at a time. Such a device would be preferable to any form of feedback presented in the present study for this purpose.

Third, Baldwin suggested that feedback should allow comparison with past performance. Cumulative feedback allows these comparisons to be made; however, the consumer is generally required to keep records to facilitate this process. If the final cumulative daily feedback value is saved for 24 hours, then a simple inspection of the 
display will allow comparisons between the current daily cumulation and that of the previous day. The use of instantaneous feedback for comparison purposes is somewhat obscure to participants due to its constantly changing values.

Seligman notes that feedback should be given in a form that is most meaningful to the homeowner. Cumulative feedback appeared to be the most understandable form of feedback in terms of its purpose and derivation. Participants reported some confusion over the purposes and derivation of projected and instantaneous feedback. Participants questioned the credibility of these latter feedback types since the values displayed are estimates which make what they consider to be some unrealistic assumptions about behavior and energy use. For example, hourly instantaneous feedback provides an estimate of energy cost that assumes that you continue to use energy at the same rate for an hour; projected daily feedback assumes that energy will be used at the same rate tomorrow as it was today. Given participants' reactions, instantaneous and projected feedback are not recommended as forms of energy feedback for consumer use. If care is taken to insure adequate education about the meaning and use of these forms of feedback, some of the problems in meaningfulness and understandability may be alleviated. The question still remains whether instantaneous and projected feedback are suited for the uses which consumers will make of energy cost feedback information.

Seligman has also said that feedback should be nonabrupt in showing changes from one presentation to another. Instantaneous feedback does not meet this criterion because the values displayed are subject to momentary variations in energy usage, thus affecting cost estimates from moment to moment. Projected feedback may also show abrupt changes in energy cost estimates from day to day since projected feedback is always based on the previous day's energy cost. There may be ways to avoid the abruptness problem by averaging feedback over several days or by eliminating quantitative feedback in favor of some simpler reinforcing signal system.

In summary, it is recommended that a feedback meter incorporate a daily cumulative feedback display, the final total of which can be saved for the next 24 hours on a separate display. This would allow the user to monitor energy use of individual appliances as well as patterns of appliance use. Second, a monthly cumulative feedback figure should be provided since consumers found it useful for budgetary purposes. Any additional energy cost information 
could be easily supplied by educational materials rather than by an hourly instantaneous feedback display. Since the use of an hourly instantaneous feedback display for monitoring energy consumption of individual appliances was expected to be of only short term value by the participants, the third recommendation is that careful consideration be given to including hourly instantaneous feedback as a part of energy cost feedback meters. All energy cost figures should be displayed as separate energy costs (e.g. gas and electric) where applicable to facilitate consumer use of energy cost information.

Future Research Areas

Becker and Seligman (in press) cite data suggesting that feedback does not necessarily need to be quantitative. In that study, a blue flashing light was used to signal air-conditioner operation when the outside temperature was below $68^{\circ} \mathrm{F}$. Results indicated that the blue light alone was sufficient to cause a reduction in energy consumption. An empirical field study should be conducted to further investigate the effectiveness of nonquantitative feedback.

Participants in the present study indicated that their use of hourly instantaneous feedback may be short-lived. The effects over time of the various types of energy-cost feedback need to be studied in order to develop feedback meters capable of maintaining reduced energy consumption and at the same time incorporating a cost-effective design.:

Another avenue of future research involves investigating individual versus group feedback. Baldwin (1977) has suggested that comparing consumer's energy consumption to a group norm may have a motivating effect on conservation-"keeping up with the Joneses." Further work in this area will help clarify the relative effectiveness of individual and group feedback.

As a laboratory-based study, the present study did not allow a statistical evaluation of the effectiveness of the various types of feedback. The effectiveness of feedback is best tested using field study techniques. Appendix I contains a proposal for such a field study, designed to determine the effectiveness of the feedback types investigated in the present study.

If the effectiveness of a particular type of feedback is verified, its application to other types of conservation should be investigated. An example of an area in which feedback may prove beneficial is in water conservation. 
Another possible use of energy feedback involves installing a device which displays a cost value for energy use of individual appliances. This would allow the consumer to see the cost of using a single appliance at a time. The value of providing such feedback for individual appliances may be tested to determine the effect of such information on energy conservation efforts and appliance use.

Only a few possible research areas have been mentioned here. As more data is obtained on the effects of feedback on conservation behavior, it will become desirable for these data to be assimilated and a general theory of conservation/consumption feedback developed. Such a theory could facilitate the use of these data in reducing consumption of other limited resources. 
Baldwin, F.D. Meters, bills, and the bathroom scale, Public Utilities Fortnightly, February 3, 1977.

Becker, L.J. and Seligman, C. Reducing air-conditioning waste by signalling it is cool outside. Personality and Social Psychology Bulletin, in press.

PEPCO Study, personal communication with L. Collins, Chief, Consumer Motivation Branch at the U.S. Department of Energy, January 1978 .

Seligman, C. Why does feedback facilitate residential energy conservation? Paper presented at the 1978 Annual Meeting of the Human Factors Society, Detroit, Michigan. October 16-19, 1978 .

Seligman, C., Darley, J.M. and Becker, L.J. Psychological strategies to reduce energy consumption: First annual progress report, Center for Environmental studies Report No. 41, Princeton, N.J., November, 1976.

Winett, R.A., Kaiser, S. and Haberkorn, G. The effects of monetary rebates and daily feedback on electricity conservation, Journal of Environmental Systems, in press.

Winett, R.A., Neale, M., Williams, K., Yokley, J. and Kauder, H. Preliminary report on the use of feedback to promote residential electricity conservation, Institute for Behavioral Research, Inc.. Silver Spring, Maryland, Summer, 1977. 


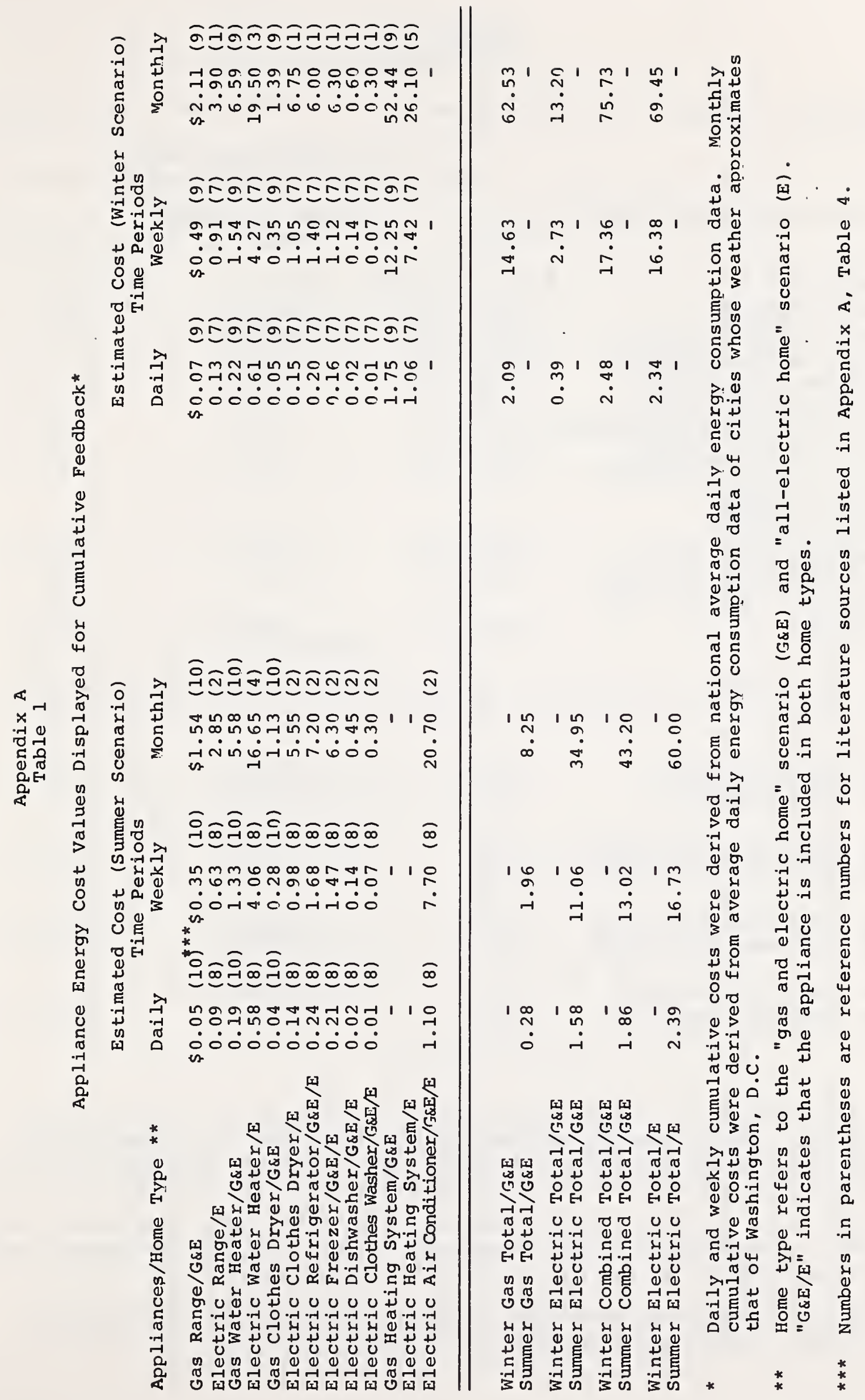


Appliance Energy Cost Values Displayed for Instantaneous Feedback

Estimated Cost

(Both Winter and Summer Scenarios)

Appliances/Home Type**

Time Periods

Hourly

Gas Range/G\&E

Electric Range/E

Gas Water Heater/f\&E

Electric Water Heater/E

Gas Clothes Dryer/G\&E

Electric Clothes Dryer/E

Electric Refrigerator/G\&E/E

Electric Freezer/G\&E/E

Electric Dishwasher/G\&E/E

Electric Clothes

Washer/G\&E/E

Gas Heating System/G\&E

Electric Heating System/E

Electric Air Conditioner

$\mathrm{G} \& \mathrm{E} / \mathrm{E}$

$\begin{array}{ll}\$ 0.18 & (13) * * * \\ 0.61 & (11) \\ 0.62 & (13) \\ 0.12 & (11) \\ 0.08 & (13) \\ 0.24 & (11) \\ 0.02 & (14) \\ 0.02 & (14) \\ 0.06 & (11) \\ 0.03 & (11) \\ 0.83 & (13) \\ 1.00 & (12) \\ 0.20 & (12)\end{array}$

Daily

$\$ 4.32$

14.64

14.88

2.88

1.92

5.76

0.48

0.48

1.44

0.72

19.92

24.00

4.80
Monthly

$\$ 129.60$

439.20

446.40

86.40

57.60

172.80

14.40

14.40

43.20

21.60

597.60

720.00

144.00

$\begin{array}{lrrr}\text { Winter Gas Total/G\&E } & 1.71 & 41.04 & 1231.20 \\ \text { Summer Gas Total/G\&E } & .88 & 21.12 & 633.60 \\ \text { Winter Electric Total/G\&E } & 0.13 & 3.12 & 93.60 \\ \text { Summer Electric Total/G\&E } & 0.33 & 7.92 & 237.60 \\ \text { Winter Combined Total/G\&E } & 1.84 & 44.16 & 1324.80 \\ \text { Summer Combined Total/G\&E } & 2.04 & 48.96 & 1468.80 \\ & & & \\ \text { Winter Electric Total/E } & 2.10 & 50.40 & 1512.00 \\ \text { Summer Electric Total/E } & 2.30 & 55.20 & 1656.00\end{array}$

* Daily and weekly cumulative costs were derived from national average daily energy consumption data. Monthly cumulative costs were derived from average dailv energy consumption data of cities whose weather approximates that of Washington, D.C.

** Home type refers to the "gas and electric home" scenario (F\&E) and "all-electric home" scenario (E). "G\&E/E" indicates that the appliance is included in both home types.

*** Numbers in parentheses are reference numbers for literature sources listed in Appendix A, Table 4. 


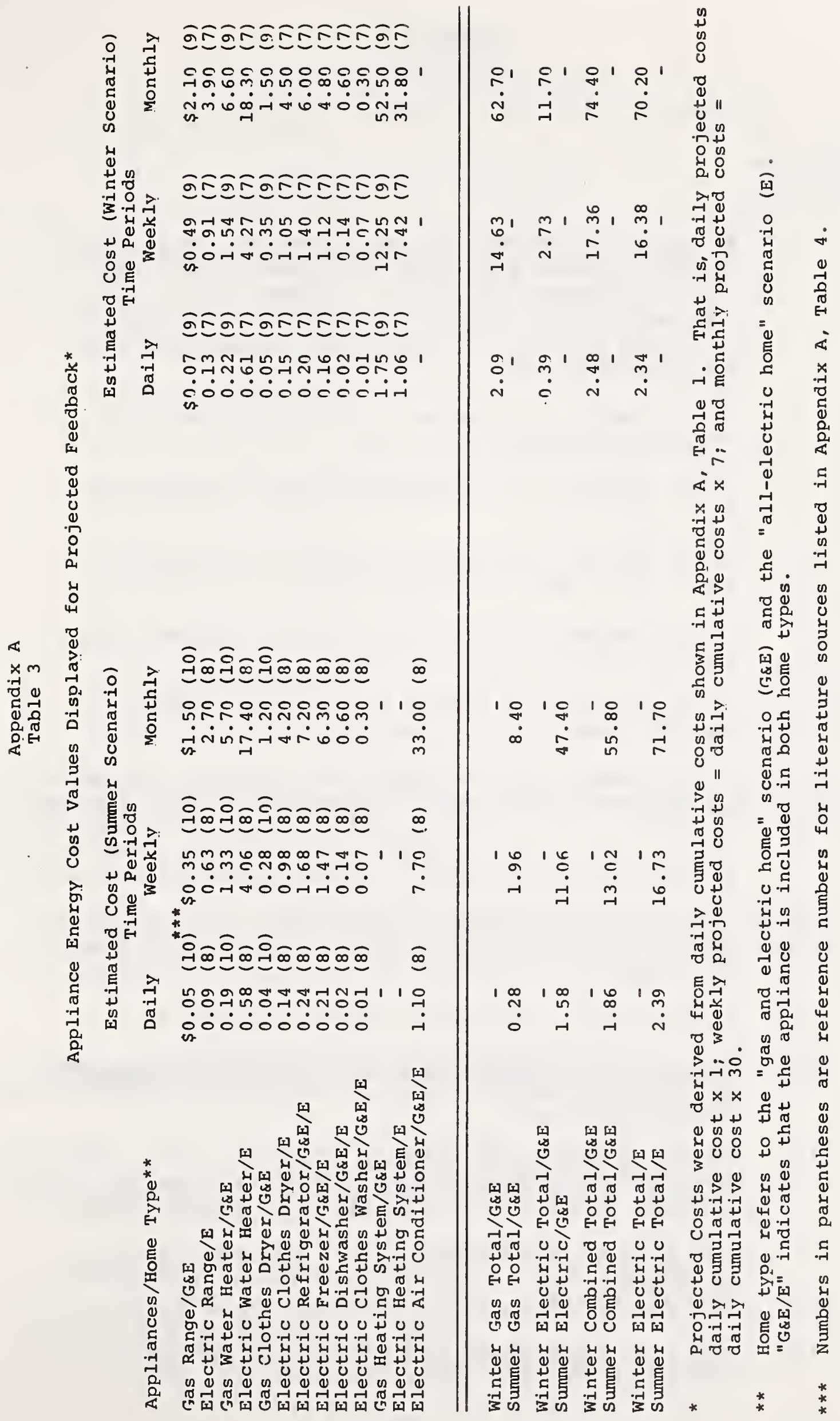



Appendix A
Table 4
Literature Sources for Energy Cost Estimates

Reference

Number

Source

1 Patterns of Energy Use by Electrical Appliances Study, Midwest Research Institute, Final report to U.S. Department of Energy, January 1978, Table D-3, "Average Daily Electric Consumption by Appliance, City and Month", January Electric Consumption, Philadelphia, Pa.

2 Ibid, Table D-3, August Electric Consumption, Philadelphia, Pa.

3 Ibid, Table D-3, January Electric Consumption, St. Louis, Mo.

4 Ibid, Table D-3, August Electric Consumption, St. Louis, Mo.

5 Ibid, Table D-3, January Electric Consumption, Boston, Mass.

6 Ibid, Table D-3, August Electric Consumption, Boston, Mass.

7 Ibid, Table 5-3, "Average Daily Electric Consumption by Appliance Per Month", Januarv Electric Consumption

8 Ibid, Table 5-3, "Average Daily Electric Consumption by Appliance Per Month", August Electric Consumption

9 Gas Facts: 1976 Data. Arlington, Va.: American Gas Association, 1971, Table 107, January Therm Consumption, p. 129

10 Ibid, Table 107, August Therm Consumption

11 Annual Energy Requirements of Electric Household Appliances, Edison Electric Institute, EEI-Publication \#75-61 Revision

12 Sears, Roebuck and Company Catalog, 1978, (derived approximation of average wattage ratings for electric heating systems and electric air conditioners).

13 Gas Engineers Handbook: Fuel ras Engineering Practices, N.Y.: Industrial Press, First Edition, Second Printing, 1966. Table 9-24, p.9/63

14 The U.S. Fact Book: The American Almanac, N.Y.: Grosset \& Dunlap, 1976, Table 891, p. 537. 
Energy Usage Questionnaire

1. Do you use electricity
a. for lighting, cooking, and other appliances
b. for air conditioning?
c. for hot water?
d. for heating your home?

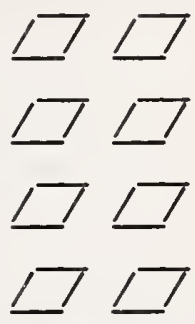

2. Do you use natural gas
a. for cooking or other appliances?
b. for air conditioning?
c. for hot water?
d. for heating your home?
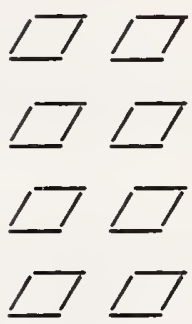

3. Do you use fuel oil
a. for hot water?
b. for heating your home?

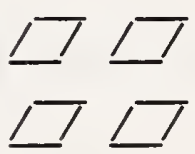

4. What portion of your monthly income do you spend for energy (including gas, electricity, fuel oil, etc.) in the winter? For example, $1 / 3,1 / 2,1 / 4$, etc.

5. What portion of your monthly income do you spend for energy (including gas, electricity, fuel oil, etc.) in the summer? For example, $1 / 3,1 / 2,1 / 4$, etc.

6. Do you know how the utility companies charge you for your energy usage? How?

7. Do you know how much you are charged per kilowatt hour (for electricity) and per therm (for gas)? How much?

8. Do you think people should conserve energy usage in their homes whenever possible? Why? 
9. Do you try to conserve energy in your home?

10. If you said yes, why do you conserve energy in your home?

If you said no, why don't you conserve energy in your home?

11. What do you do in your home to conserve energy?

12. Do you regularly check your electricity meter?

13. What other things could you do to conserve energy in your home?

14. Do you now know how much energy you are using?

15. Do you think you have great daily variations in your energy usage?

16. Do you think that if you had more information about energy use that it would help you reduce your own use of energy?

17. What kind of information do you need to help you use energy more efficiently in your home?

18. If you had this extra information how would you use it? 
19. Do you think it would help you to have more information about how much energy the different appliances in your home use?

20. If you had this information, how would you use it?

21. What could the utility companies do to help you conserve energy and reduce your energy usage? 

Feedback Explanation

The purpose of this study is to evaluate energy cost feedback. What is energy cost feedback? Basically, it tells you how much the energy you are using is costing you. There are numerous ways in which energy cost information can be presented. The one you are perhaps most familiar with is your monthly utility bill. Another way to show energy cost information is to place a meter directly in the home. The meter then would have one or more displays showing the cost of your energy usage.

The role you will be playing in this study will be to tell us what energy cost information you feel would help you most as a consumer. We are assuming that most consumers want to conserve energy, if for no other reason than to save money. We will be showing you a number of different types of energy cost displays. Then we'll ask you for your reactions to them. Do you have any questions so far about energy cost feedback?

I'll spend a few minutes now describing the kinds of feedback displays you'll be looking at. First, there are three main ways in which energy cost can be presented. These are, first, by cumulating or adding up the cost of the energy you have used so far; second, by sampling the energy that you are presently using and providing instantaneous or immediate feedback about your current energy usage; and, third, by projecting previous energy usage to some future time period. Iet's talk about cumulated feedback first.

Cumulative energy cost feedback adds up the cost of the energy you have used so far. Energy costs can be accumulated for a day, a week, or a month. For example, you would be able to see your energy costs adding up throughout the day until at the end of the day you would be able to look at the display and see how much your energy usage had cost for that day. Then, the display would reset and the next day's accumulation would begin. If your energy cost was cumulated for a week, you could see the display adding up your energy cost until at the end of the week you would be able to look at the display and see how much your energy usage had cost for that week. Then the display would reset, and the next week's cumulation would begin. Energy costs accumulated for one month would work the same way, so that at the end of the month you would be able to see how much your energy usage had cost you for the whole month. As with the other displays, the energy cost information would be reset for the next month's cumulation. 
The second main kind of energy cost information provides instantaneous energy costs. What this basically means is that the feedback meter in the home would periodically sample how much energy is currently being used. The display would then be telling you that "if you continue to use energy at the rate you used it for, let's say, the last ten seconds, your cost at the end of the hour, day, or month would be so much money. Let's look at an hourly instantaneous estimate as an example. If you have a certain number of appliances on at once, the feedback meter would tell you that if you continue to run these appliances for one full hour, your energy cost would be $\$ 2.48$ for that hour. The values displayed for instantaneous would be updated every ten seconds or so.

The main difference between cumulated and instantaneous energy cost feedback is that cumulated feedback tells you the cost of the energy you have actually used so far; whereas instantaneous feedback tells you what your energy cost would be if you continued to use energy at the rate you are now using it.

These two concepts may seem somewhat confusing to you. I'd like you to take a few minutes to tell me in your own words what instantaneous feedback is and what cumulative feedback is.

The third type of energy cost feedback is projected feedback. Projected feedback is based on the previous day's energy cost. That is, if yesterday's energy cost was $\$ 5.00$, the projected weekly value would be $\$ 35$ or $\$ 5.00 \mathrm{x}$ seven days. The projected monthly value would be $\$ 150$ or $\$ 5.00$ x 30 days. Of course, the projected daily value would be the same as yesterday's cost since it is equal to yesterday's cost times one. Projected feedback tells you what your energy usage will cost if you continue to use energy at the same rate as yesterday. The values displayed for projected feedback would change each day based on the energy cost of the previous day.

I'd like you to take a few minutes to tell me in your own words what projected energy cost feedback is.

The difference then between projected energy cost feedback and cumulative feedback is that projected feedback tells you what your daily, weekly or monthly energy costs would be if you continued to use energy as you had yesterday; whereas, cumulative feedback tells you the cost of the energy you have actually used so far that day, week or month. 
The difference between projected energy cost feedback and instantaneous feedback is that projected feedback is based on yesterday's energy cost, while instantaneous feedback tells you what your energy cost would be for an hour, day or month if you continued to use energy at the rate you are presently using it.

Now please describe in your own words what the differences are between instantaneous, projected and cumulative feedback.

So far we have talked about what energy cost feedback is in general and about three main kinds of feedback, that is, cumulative, instantaneous, projected feedback. The next thing that you will need to know about energy cost information is that your energy cost can be broken down into its major components. In this study, we will be talking about gas and electric costs as the two major components of total energy cost. So in addition to having a total energy cost value, you could have an electric cost value and a gas cost value displayed separately.

Let's quickly review what we've gone over so far. 1) cumulative energy cost feedback adds up the cost of your energy usage so far. Cumulation time periods are daily, weekly or monthly. 2) For instantaneous energy cost feedback, your energy usage rate would be periodically sampled (let's say every ten seconds). The display would then tell you what your energy cost would be if you continued to use energy at that rate for a certain time period. Instantaneous time periods are hourly, daily or monthly. 3) Projected energy cost feedback tells you what your energy usage will cost if you continue to use energy at the same rate as yesterday. The time periods associated with projected feedback are daily, weekly and monthly. 4) For all three types of energy feedback, energy cost can be presented as a total or be broken down into gas and electric.

Do you have any questions now? 


\section{.}




\section{APPENDIX D \\ Equipment Explanation}

The equipment used for this study has four basic components: 1) a computer which will produce the displayed energy cost values; 2) a feedback meter that can display as few as one or as many as six different values at one time; 3) a terminal which will allow you to simulate appliance usage by either turning on or off appliances, thus allowing you to see the changing values on the display, and which will print out questions for you to answer and remind you which appliances are on and which are off; and 4) a tape recorder into which you will talk as you go through the session allowing you to make comments or suggestions while they are fresh in your mind.

The values you will see on the feedback meters are for eight major appliances. The energy cost values you will see are based on average usage of the appliances and are not intended to represent your actual usage of these appliances. Because you may not use appliances as they are shown here and because other energy users within the home are not included, the energy cost values you see displayed will not represent your utility bill.

The type of appliances that you would have in your home depend upon whether you have an all electric home or a gas and electric home. (If participant has a gas and electric or oil and electric home, read:) So we will show your energy costs as a total as well as gas and electric costs separately. (If participant has an all electric home, read:) Since you have an all electric home, we will show your cost for electricity only.

Another factor that would determine what appliances would be on at any given time is the season of the year. For example, you don't run the air conditioner in the winter and the heater in the summer. So we will present values on the displays that are based on summer appliance usage or winter appliance usage. 



\section{APPENDIX E \\ Cumulative Feedback Interview Guide}

1. What information does cumulative daily feedback give you?

2. How can cumulative daily energy cost feedback be used?

3. What information does cumulative weekly feedback give you?

4. How can cumulative weekly energy cost feedback be used?

5. What information does cumulative monthly feedback give you?

6. How can cumulative monthly energy cost feedback be used?

7. Which time period (day, week, month) do you prefer for cumulative energy cost feedback? Why?

8. At what time of the day would you want the daily cumulative display to clear and start the next day's cumulation?

9. Do you think that your daily cumulative meter reading should be saved? That is, would you want to be able to see what yesterday's meter reading was? Why?

10. What did you find confusing about cumulative feedback?

11. Should cumulative energy cost information be provided separately for gas and electricity or as a total? Why? 


$$
\begin{gathered}
\text { APPENDIX F } \\
\text { Instantaneous Feedback Interview Guide }
\end{gathered}
$$

1. What information does instantaneous hourly feedback give you?

2. How can instantaneous hourly energy cost feedback be used?

3. What information does instantaneous daily feedback give you?

4. How can instantaneous daily energy cost feedback be used?

5. What information does instantaneous monthly feedback give you?

6. How can instantaneous monthly energy cost feedback be used?

7. Which time period (hour, week, month) do you prefer for instantaneous energy cost feedback? Why?

8. What amount of time should be sampled to provide an instantaneous estimate of energy cost?

9. What did you find confusing about instantaneous feedback?

10. What do you like/dislike about an instantaneous energy cost estimate?

11. Should instantaneous energy cost information be provided separately for gas and electricity or as a total? Why? 


$$
\begin{gathered}
\text { APPENDIX G } \\
\text { Projected Feedback Interview Guide }
\end{gathered}
$$

1. What information does projected daily feedback give you?

2. How can projected daily energy cost feedback be used?

3. What information does projected weekly feedback give you?

4. How can projected weekly energy cost feedback be used?

5. What information does projected monthly feedback give you?

6. How can projected monthly energy cost feedback be used?

7. Which time period (day, week, month) do you prefer for projected energy cost feedback? Why?

8. What did you find confusing about projected feedback?

9. What do you like/dislike about a projected energy cost estimate?

10. Should projected energy cost information be provided separately for gas and electricity or as a total? Why?

11. Should projected energy cost information be based on yesterday's cumulative value or some other time period? 
. 
"This chart shows all the possible types of feedback we have examined. Think about them and decide which one(s) you would personally like to use to design your own feedback meter. You can have any combination of projected, cumulative and instantaneous feedback and may use as many or as few displays as you think you would really use.

As you select the information you want, we will display the information for you so you can see how it would work. Feel free to charge your mind at any time."

For each display chosen, ask:

Why did you pick feedback?

How would you use this information?

Why did you choose this particular combination of displays?

Is there any other information you would like displayed? 
(If more than three displays chosen, ask subject to limit choices to three)

Why did you choose this particular combination of displays? 


\section{APPENDIX I \\ DOE Prototype Meter Interview Guide}

Enter this combination:

cumulative daily

cumulative monthly

cumulative hourly

Suppose I were to design this energy feedback meter. What do you think of this sample feedback meter?

How could you use this information?

What do you like about this particular combination?

What do you dislike about this particular combination?

What time of the day should the daily cumulative display clear and start the next day's cumulation? Why?

Should your previous day's energy cost be stored on a separate display? 
APPENDIX J

Final Interview

1. Which kind of energy cost feedback is most meaningful or helpful for you? Why?

2. How many kinds of information should an energy cost feedback meter provide to the consumer?

3. How does cumulative daily energy cost feedback differ from projected daily energy cost?

4. How does instantaneous energy cost differ from projected energy cost?

5. How does cumulative energy cost differ from instantaneous energy cost?

6. What do you like/dislike about cumulative energy cost information?

7. What do you like/dislike about instantaneous energy cost information?

8. What do you like/dislike about projected energy cost information?

9. What is not clear about how to use energy cost information?

10. What additional information should be displayed on an energy cost feedback meter? 
11. Do you think information about your energy cost would be helpful to you in saving energy in your home? How would you use this information?

12. What did you find confusing about cumulative feedback?

13. What did you find confusing about projected feedback?

14. What did you find confusing about instantaneous feedback?

15. Given the cost of your energy today, do you think you would buy and use an energy feedback meter? Why?

16. How expensive would energy have to become before you would buy and use an energy feedback meter? Why?

17. What kinds of instructional materials should accompany an energy cost feedback meter?

For instance--what kind of information should be provided

a. for how to read your meter?

b. for what the numbers mean and how they could be used?

c. for what each display on the meter represents and how they could be used?

d. about the cumulative display and how it resets at the end of a certain time period?

e. about appliance energy consumption?

f. about how to conserve energy? 
g. about money saved by using various thermostat settings?

h. about the difference between meter reading and actual energy bills? 


\section{APPENDIX K \\ Human Factors Considerations for Energy Feedback Meters}

Introduction

A system designed for ease of operation inspires confidence and increases efficiency. In a time of increasing energy demand and dwindling fuel supplies it would be a disservice to the consumer to develop a potential energy saving device that did not attend to the capabilities and limitations of the user. The consideration of the human element has been proven to be a significant factor in maximizing human performance reliability (DeGreene 1970), thereby contributing to the overall success of the system.

The interface between the energy feedback meter and the individual is relatively simple. Attention on the part of the manufacturer to a few specific recommendations in some cases and consideration of minimum requirements in others will insure an optimal man-machine interaction. Three specific areas are addressed: display construction, the labeling of the feedback meter and the placement of the meters.

\section{Display Construction}

Safety considerations dictate that the size of the unit should not extend beyond $6.35 \mathrm{~cm}$ from the wall (McCormick 1970). In addition, the unit should not exceed $30.48 \mathrm{~cm}$ in height and the width should be approximately 80 percent of the height.

Visual displays should be arranged so as to minimize eye movements and present important information in easilyseen locations. Rules for the arrangement of visual displays (Van Cott 1972, McCormick 1970) include:

- Placement of the displays in front of the operator, as nearly perpendicular to the individual's line of sight as possible,

- All the displays necessary to support the feedback process should be grouped together,

- When multiple displays are grouped together, the displays should have brightness uniformity, 
- A minimum height of $1.02 \mathrm{~cm}$ is sufficient to enhance the readability of the numeric figures at a distance of $152.4 \mathrm{~cm}$, well beyond the optimal viewing distance of $71.12 \mathrm{~cm}$,

- The displays should be mounted as close as possible to the panel surface so as to minimize parallax and maximize viewing angle.

- Transilluminated light emitting diodes (LED) and liquid crystal diodes, can be purchased off the shelf to meet or exceed the minimum recommended size of the numeric characters (AFSC 1970).

- Transilluminated displays should be constructed, arranged and mounted to prevent reduction of information transfer due to the reflection of ambient illumination from the display (AFSC 1970).

- The luminance contrast within the indicator should be at least 50 percent under normal operating conditions. Since the displays are likely to be used under varied ambient illuminance, a dimming control should permit the displays to be legible under all expected ambient illuminance (AFSC 1970).

Labeling

The labeling of the energy feedback meters can have a significant effect on the individual's ability to utilize the device (AFSC 1970). Below is a set of guidelines (AFSC 1970) which will assist the manufacturer in optimizing the effectiveness of these labels:

- Label the indicators in terms of what is being measured, not by the name of the device.

- Label the indicators in the most simple and direct manner possible.

- Make the labels as brief as possible, but do not use abreviations, unless they are familiar to all the expected consumers.

- Position the labels so that numerical designations are not crowded or obstructed, and 
- Do not include company names or trade names on the usable portion of the display.

- Capital letters ("all caps") are recommended. The recommended size of the alphanumeric characters should have a width height ratio of $3: 5$, except for the "l" which should be one stroke width wide. The stroke width should be $1 / 6$ to 1.8 of the height (Van Cott 1972).

\section{Location}

Displays should be located and designed so that they may be read accurately in the normal standing position (McCormick 1970, Van Cott 1972). The normal line of sight of individuals is about $15^{\circ}$ below the horizon (Haber and Hershenson 1973). Limited eye and head movements permit a fairly convenient visual scanning of an area roughly $15^{\circ}$ around the normal line of sight--up and down and sideways. This area defines the approximate optimum location for visual displays. However, the neighborhood areas are also reasonably satisfactory for visual displays, such as the angle from the horizontal down to about $35^{\circ}$ to $45^{\circ}$ and a total lateral range of about $45^{\circ}$ to $60^{\circ}$ from a straight ahead direction.

\section{Summary}

It is not the intent of this section to present inflexible specifications from which the feedback meter should be developed and it is not requisite that the recommendations be followed stringently. Rather they serve to provide a simple mechanism for considering the human performance capability within the framework of the energy feedback meter.

\section{References}

Air Force Systems Command Design Handbook Series 1-3, Human Factors Engineering, 1 December 1970. WrightPatterson AFB OH 45433.

DeGreene, K.B. Systems Psychology, McGraw Hill, Inc. New York, 1970 .

Haber, R.N. and Hershenson, M. The Psychology of Visual Perception. Holt Rinehart and Winston, Inc. New York, 1973. 
McCormick, E.J. Human Factors Engineering ( 3 rd ed)

McGraw Hill Book Company, New York, 1970.

Van Cott, H.P. and Kinkade, R.G. (ed) Human Engineering Guide to Equipment Design (Rev. Ed.) McGraw Hill Company, New York, 1972. 
A. Proposal for Field Testing

Energy-Cost Feedback Meters

Background

A research effort resulting in human factors recommendations for performance characteristics of energy-cost feedback devices was conducted by the Consumer Ergonomics and Information Group at the National Bureau of Standards. This effort supported the work being done by DOE's Consumer Motivation Branch (CMB) in the area of energy-cost feedback. Interviewing techniques were used to provide consumer reaction to various types of energy-cost feedback. The issues addressed included: consumer motivation to use energy feedback meters; mearingfulness and usability of various types of feedback; preferences among the various feedback types; and, educational or instructional materials to accompany feedback meters.

Since information collected on the above issues was not based on actual usage of energy-cost feedback meters by consumers in their homes, recommendations made to DOE's Consumer Motivation Branch should be evaluated in the field. CMB now plans to conduct a field demonstration project to illustrate to manufacturers, utilities, and consumers the usefulness of energy feedback meters in reducing residential energy consumption by providing only one fixed meter design. It is the objective of this proposal to demonstrate the feasibility of performing a more detailed field evaluation of various meter designs without significantly increasing the cost over that of the demonstration project.

\section{Proposed Study}

It is proposed that a field experiment be conducted rather than simply a demonstration project. Through a field study it would be possible not only to demonstrate the usefulness of residential energy-cost feedback, but it would make field testing the efficacy of several types of energy feedback. meters possible.

The energy-cost feedback meter that DOE is considering for use in its demonstration project incorporates three types of information. These are: a) daily cumulative feedback (DCF)--constantly monitors energy usage and displays a cumulation of the cost of energy consumption for a 24-hour period, b) monthly cumulative feedback (MCF)--constantly monitors energy usage and displays a running cumulation of the cost of energy consumption for a monthly period, and 
c) hourly instantancous feedback (IIIF)--monitors current energy usage and estimates what the cost would be if consumption continued at that rate for one hour. The device samples energy use and updates the display every 15 seconds. A fourth type of energy-cost information that will be'.presented is yesterday's daily cumulative feedback total figure (YDCF). According to DOE's plan, DCF will be constantly displayed on the feedback meter. When the consumer wishes to view any of the remaining three types of information (MCF, HIF, or YDCF) the consumer would push a button, causing the desired information to be temporarily displayed.

The field study design being proposed by NBS would allow the consumer an opportunity to use various combinations of the above-mentioned feedback types. The difference between DOE's meter design and that proposed by NBS is that the NBS meter design would contain a switch that is not accessible by the participant and which would be set by field personnel to activate the particular feedback combination to which participants will be exposed. As with the DOE plan, the energy-cost feedback meter utilized in the proposed study will include one type of energy feedback displayed constantly and others that will be displayed when the consumer/participant engages a push-button. So, participants in the field study would be provided with an energy cost feedback meter containing one constant display that can be momentarily changed by the consumer to display one of three other types of feedback. The YDCF display need not be included in the field experiment as an independent variable since this display is a convenience feature only and would not foreseeably be used differently than DCF for controlling energy consumption. However, all experimental participants will be allowed to push a button to have this figure displayed.

\section{Experimental Design}

The four experimental conditions which will be employed are illustrated in Table 1 . In condition $A$, the DOE feedback meter participants will use a feedback device in which daily cumulative feedback is displayed constantly, while hourly instantaneous feedback and monthly cumulative feedback will be displayed when the participant engages a push-button. In condition $B$, hourly instantaneous feedback will be constantly displayed, and daily cumulative feedback and monthly cumulative feedback can be displayed by pushing a button. Cumulative monthly feedback is displayed constantly in condition $C$, with hourly instantaneous feedback and daily cumulative feedback being displayed when a button is pushed. In condition $D$, preference data will be collected by allowing the participants to choose whether they prefer to see either condition A, B, or C again for the final quarter. 
Table 1

Four Experimental Conditions

\begin{tabular}{c|l|l}
\hline Condition & $\begin{array}{c}\text { Constant } \\
\text { Display }\end{array}$ & \multicolumn{1}{c}{$\begin{array}{c}\text { Optional } \\
\text { Displays }\end{array}$} \\
\hline A & DCF & MCF, HIF, YDCF \\
B & HIF & DCF, MCF, YDCF \\
C & MCF & DCF, HIF, YDCF \\
D & Participant's Preference \\
\hline. & \multicolumn{2}{|}{} \\
\hline
\end{tabular}

; 
The design of the proposed field study is illustrated in Table 2. It is proposed that a minimum sample size of 500 be incorporated, with 100 participants being assigned to each of the five matched groups distributed cqually across the demonstration areas. Presentation of the feedback conditions $A, B$, and $C$ will be counterbalanced.

Participants in Group I will remain in condition A for one full year. Group 2 will be in condition A for three months, then condition B for three months, followed by condition $C$ for three months. Group 3 will view feedback meters with condition $B$ presented in the first quarter, condition $C$ in the second, and condition $A$ in the third. Group 4 will first be exposed to condition $C$, then condition $A$, and then condition B. Participants in groups 2, 3 and 4 will choose their preferred condition for use during the final quarter, condition D. Group 5 is the control group and will receive no energy cost feedback.

\section{Experimental Measures}

All groups will be constructed so as to insure that they are matched in terms of energy consumption prior to installation of the energy-cost feedback meters. At the end of each three-month period, energy consumption readings will be made at each household in the experimental groups (groups I through 4) and the control group (group 5).

Comparisons of energy consumption will be made to determine the effects of the conditions and orders. Those comparisons are illustrated in Table 3. It can be seen that a great deal of data can be gathered by conducting an experimental field study as opposed to a simple demonstration project. If a demonstration project alone was conducted, only comparisons 1 and 5 could be made.

At the end of each quarter, measures will also be taken of the frequency with which participants select each of the two available optional displays. In this connection, "optional displays" refer to the two feedback types that are accessible by pushing buttons on the feedback meters. Frequency data will be analyzed using an analysis of variance to determine whether any preferences are shown in optional feedback types accessed.

In addition to taking readings of energy consumption and feedback selection frequencies for each quarter, written or oral questionnaires will be administered to the participants. In this way, insights can be gained to determine subjective reactions to the various types of energy-cost. feedback meters. Without compromising the intent of the demonstration project and at minimum additional cost, a more detailed evaluation of device effectiveness can be conducted. 
Table 2

12 Month Test Period

\begin{tabular}{|c|c|c|c|c|}
\hline Test Groups & $\begin{array}{c}1 \text { st } \\
3 \text { Months }\end{array}$ & $\begin{array}{c}\text { 2nd } \\
3 \text { Months }\end{array}$ & $\begin{array}{c}\text { 3rd } \\
3 \text { Months }\end{array}$ & $\begin{array}{c}4 \text { th } \\
3 \text { Months } \\
\end{array}$ \\
\hline 1 & A & A & A & A \\
\hline 2 & A & B & C & D \\
\hline 3 & B & C & A & D \\
\hline 4 & C & A & B & $D$ \\
\hline 5 & Con & col Condi & $o n-$ no $f$ & dback \\
\hline
\end{tabular}




\section{Comparison}

Between Groups

1. Group 1 to Group 5

Quarters 1 thru 4 individually and annual total

2. Groups (2, 3, and 4) to Group 5

Quarters 1 thru 3 individually and annual total

3. Group 1 to Groups ' $(2,3$, and 4)

Final Quarter

4. Group 2 to Group 3

Group 2 to Group 4

Group 3 to Group 1

Quarters 1 thru 3 totals

Within Groups

5. Group 1

Compare each Quarter to each other Quarter

6. Across Groups 2, 3, and 4 compare Condition A to Condition B to Condition C
Purpose

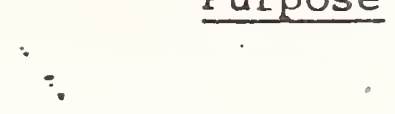

Describe differences in enexgy consumption between Experimental Condition $A$ and the control Condition

Describe differences in energy consumption between the counterbalanced presentation of experimental Conditions $A, B$, and $C$ and the Control Condition

Describe differences in energy consumption between a forced choice. (Condition A) and a preferred choice (Condition D)

Describe any order effects

Describe the effects on energy consumption of the Condition A device over time

Describe the main effects of treatment conditions (are there differences in energy consumption between Condition A, Condition B, and Condition $\mathrm{C}$ ) 
NBS-IIAA (REV. 0.78)

\begin{tabular}{|c|c|}
\hline $\begin{array}{c}\text { U.S. DEPT. OF COMM. } \\
\text { BIBLIOGRAPHIC DATA } \\
\text { SHEET }\end{array}$ & $\begin{array}{c}\text { 1. PUBLICATION OR REPORT NO. } \\
\text { NBSIR } 79-1771\end{array}$ \\
\hline
\end{tabular}

4. TITLE AND SUBTITLE

An Investigation of Preferences for Various Types of Energy Cost Feedback

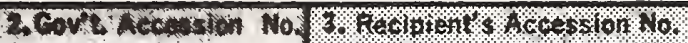

5. Publication Date

August 1979

6. Portorming Organization Code

8. Performing Organ. Report No.

7. $\operatorname{AUTHOR}(S)$

Ann Ramey-Smith and Jennifer L. Gagnon

9. PERFORMING ORGANIZATION NAME AND ADDRESS

NATIONAL BUREAU OF STANDARDS

DEPARTMENT OF COMMERCE

WASHINGTON, DC 20234

12. SPONSORING ORGANIZATION NAME AND COMPLETE ADDRESS (Stroet, City, state, zIP)

U. S. Department of Energy

Consumer Motivation Branch

Washington, D.C. 20545

10. Project Task/lork Unit No.

11. Contract/Grant No.

13. Type of Report \& Period Covered

Final

16. SBshoring Rgency code

15. SUPPLEMENTARY NOTES

Document describes a computer program; SF-185, FIPS Software Summary, is attached.

16. ABSTRACT (A 200-word or lose factual summary of most significant information. If document includes a significant bibliography or literature survey, mention it here.)

The present study addressed the issue of consumer preferences for various types of energy cost feedback for individual consumers. Its purpose was to provide human factors recommendations to DOE related to the performance characteristics of energy cost feedback devices for use by DOE in testing energy cost feedback meters. Simulation and interview techniques were used to provide consumer reaction to cumulative, instantaneous, and projected feedback presented as dollar and cent values. A majority of participants indicated a preference for cumulative feedback types. All types of cumulative feedback are easily understood, accurate in reflecting actual energy consumption and suitable to several uses. Hourly instantaneous feedback was considered useful for monitoring energy use of individual appliances. All participants having two energy sources in their home expressed a preference for having feedback presented as separate cost figures rather than as a total cost. Recommendations for feedback types as well as some performance characteristics of energy cost feedback meters for further testing by DOE are discussed.

17. KEY WORDS (aix to twelve entries; alphabetical order; capitalize only the firat letter of the firat key word unleas a proper namo; soparated by somicolona)

Attitudes; consumer preference; energy; energy cost; feedback; feedback meters
18. AVAILABILITY
XX] Unlimited

For Official Distribution. Do Not Release to NTIS

Order From Sup. of Doc., U.S. Government Printing Office, Wasinington, DC 20402, SD Stock No. SNÖ03-003-

XX Order From National Technical Information Service (NTIS), Springfield, VA. 22161

\begin{tabular}{|l|c|}
\hline $\begin{array}{l}\text { 19. SECURITY CLASS } \\
\text { (THIS REPORT) }\end{array}$ & $\begin{array}{c}\text { 21. NO. OF } \\
\text { PRINTED PAGES } \\
\text { UNCLASSIFIED }\end{array}$ \\
\hline $\begin{array}{l}\text { 20. SECURITY CLASS } \\
\text { (THIS PAGE) }\end{array}$ \\
UNCLASSIFIED
\end{tabular}



